
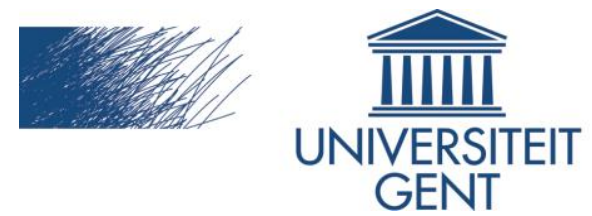

biblio.ugent.be

The UGent Institutional Repository is the electronic archiving and dissemination platform for all UGent research publications. Ghent University has implemented a mandate stipulating that all academic publications of UGent researchers should be deposited and archived in this repository. Except for items where current copyright restrictions apply, these papers are available in Open Access.

This item is the archived peer-reviewed author-version of: Evaluation of an external lubrication system implemented in a compaction simulator

Authors: Cedrine de Backere, Thomas De Beer, Chris Vervaet, Valérie Vanhoorne In: International Journal of Pharmaceutics 587, Article Number: 119675

To refer to or to cite this work, please use the citation to the published version:

Cedrine de Backere, Thomas De Beer, Chris Vervaet, Valérie Vanhoorne (2020). Evaluation of an external lubrication system implemented in a compaction simulator.

International Journal of Pharmaceutics 587, Article Number: 119675

DOI: 10.1016/j.ijpharm.2020.119675 


\section{Evaluation of an external lubrication system implemented in a compaction simulator}

Cedrine de Backere ${ }^{\mathrm{a} 1}$, Thomas De Beer ${ }^{\mathrm{b}}$, Chris Vervaet ${ }^{\mathrm{a}}$, Valérie Vanhoorne $\mathrm{a}^{\mathrm{a}^{*}}$

a Laboratory of Pharmaceutical Technology, Department of Pharmaceutics, Ghent University, Ottergemsesteenweg 460, B-9000 Ghent, Belgium

${ }^{b}$ Laboratory of Pharmaceutical Process Analytical Technology, Department of Pharmaceutical Analysis, Ghent University, Ottergemsesteenweg 460, B-9000 Ghent, Belgium

${ }^{*}$ Corresponding author

\section{Corresponding author}

Valérie Vanhoorne

Laboratory of Pharmaceutical Technology

Ottergemsesteenweg 460

9000 Ghent, Belgium

Tel: +32-9-264.80.39

E-mail address: valerie.vanhoorne@ugent.be 


\begin{abstract}
The internal blending of magnesium stearate is often associated with decreasing tensile strengths and longer disintegration and dissolution times. Therefore, external lubrication has gained interest in the pharmaceutical industry as these negative effects could be minimized using this method. In this study, an external lubrication system implemented in a compaction simulator was investigated. The influence of 2 process parameters related to the external lubrication system, spraying time and atomizing pressure, on the responses was studied using 4 common fillers and 2 model drugs. While the parameters of the external lubrication system had a significant impact on the ejection forces, no negative effect was observed on the tensile strength and disintegration time as similar values were obtained compared to non-lubricated experiments. Moreover, equal or lower ejection forces were obtained for external lubrication using a lower concentration of magnesium stearate compared to internal lubrication, where a decrease in tensile strength and prolonged disintegration was noticed for most formulations. The observed results could be correlated to the wall friction angle, compaction properties and tablet brittleness index of the raw materials and blends. This study showed the potential of external lubrication as an alternative lubrication method for lubricant-sensitive formulations.
\end{abstract}

\title{
Keywords
}

Powder compaction

Compaction simulator

External lubrication

Lubrication

Tablet properties

Magnesium stearate 


$\begin{array}{ll}\text { List of abbreviations } \\ \text { API } & \text { Active pharmaceutical ingredient } \\ \text { DCP } & \text { Dibasic calcium phosphate } \\ \text { MCC } & \text { Microcrystalline cellulose } \\ \text { MCP } & \text { Main compaction pressure } \\ \text { MgSt } & \text { Magnesium stearate } \\ \text { MPT } & \text { Metoprolol tartrate micronized } \\ \text { ICP-OES } & \text { Inductively coupled plasma optical emission spectrometry } \\ \text { PS } & \text { Paddle speed } \\ \text { rpm } & \text { Revolutions per minute } \\ \text { TBI } & \text { Tablet brittleness index } \\ \text { WFA } & \text { Wall friction angle }\end{array}$




\section{Introduction}

Tablets are the most commonly used pharmaceutical dosage form as their convenience of administration, accurate dosing, ease of manufacturing and excellent chemical and physical stability make them attractive to patients as well as manufacturers. As a result, tablets account for nearly $80 \%$ of all pharmaceutical preparations (Chen et al., 2019; Van Snick et al., 2018b). Preferably, tablets are produced by direct compression without intermediate processes such as granulation, extrusion or spray drying (Chen et al., 2019). The tableting process can be divided into three different operations: die filling, compression and ejection (Dun et al., 2020). The ejection force can be defined as the force needed to push the tablet out of the die. Frictional forces between die wall and the tablet surface during ejection can lead to high ejection forces. High ejection forces should be avoided as it causes tablet defects such as chipping, capping, lamination, picking and sticking to and wearing of the tablet tooling (Sun, 2015; Uzondu et al., 2018; Wang et al., 2010). Therefore, a lubricant is mostly added to the formulation to reduce friction between the die wall and the tablet surface. Lubricants are typically added to the formulation in concentrations of $0.5-5 \%$ ( $\mathrm{Li}$ and $\mathrm{Wu}, 2014)$. Magnesium stearate (MgSt) is the most frequently used lubricant while other commonly used lubricants include sodium stearyl fumarate and stearic acid (Sun, 2015). As a boundary lubricant with a very small particle size and large surface area, MgSt works by film layering the other powder particles resulting in less interactions between powder particles and die wall (Paul and Sun, 2017; Wang et al., 2010).

Traditionally, internal lubrication is applied where the lubricant is added to the powder mixture prior to the tableting process. However, some negative effects can be associated with internal blending of MgSt such as a reduction of the tensile strength and an increase in disintegration and dissolution time of the tablets (Bolhuis et al., 1981; Paul and Sun, 2018; Zuurman et al., 1999). These effects can be linked to the film-forming behaviour of MgSt. This lubricant coating around the powder particles inhibits the interparticle interactions with a reduced tensile strength as a result. In addition, due to the hydrophobic nature of MgSt, prolonged disintegration and dissolution times have been observed. A higher concentration of MgSt, long mixing time and high mixing intensity can further enhance these negative effects on tensile strength, disintegration and dissolution (Bolhuis et al., 1981, 1975; Bolhuis and Hölzer, 2011; Jahn and Steffens, 2005; Lerk et al., 1982; Vromans and Lerk, 1988; Zuurman et al., 1999). Moreover, the effect on tensile strength proved to be dependent on the deformation behaviour of the materials. Excipients deforming plastically, like microcrystalline cellulose (MCC), are more affected by the internal blending of MgSt, while brittle deforming excipients, such as dibasic calcium phosphate (DCP), are not influenced as fragmentation results in lubricant-free surfaces available for binding. This is in contrast to the surface of 
plastically deforming particles which is still covered with lubricant interfering with particle bonding formation, resulting in weaker tablets (Bolhuis et al., 1985; Bolhuis and Hölzer, 2011; Vromans and Lerk, 1988). In addition, the effect of paddle speed (PS) in the feed frame of a rotary tablet press on tensile strength, disintegration and dissolution time should not be neglected. As reported by Peeters et al. (2016), a higher PS reduced the tensile strength of pure MCC tablets due to over-lubrication when using a MgSt concentration of $0.5 \%$.

As internal lubrication is associated with several disadvantages, external lubrication has gained interest as an alternative lubrication method. During external lubrication, the lubricant is sprayed directly onto the tablet tooling. An external lubrication system implemented in a rotary tablet press was investigated using an eprazinone hydrochloride formulation containing 55\% lactose monohydrate (Yamamura et al., 2009). The effect of different MgSt spraying rates on tablet sticking, tensile strength and disintegration time was investigated and compared to internal lubrication. It was reported that external lubrication resulted in a $40 \%$ increase in tablet tensile strength without prolonged disintegration compared to internal lubrication. Furthermore, the minimal concentration of MgSt required to prevent powder sticking to tooling in externally lubricated tablets was only $1 / 13^{\text {th }}$ of the concentration used in internally lubricated tablets (Yamamura et al., 2009). Another study investigated the effect of MgSt spraying rate, air flow volume and rotation speed on the hardness and disintegration of an external lubrication system in a rotary tablet press (Kamiya et al., 2016). Tablets consisting of $80 \%$ lactose monohydrate and $20 \%$ MCC were prepared in this study with an internally lubricated blend with $1 \% \mathrm{MgSt}$ as a reference. Externally lubricated tablets showed a higher hardness and shorter disintegration times compared to internally lubricated tablets (Kamiya et al., 2016). Four fillers with different deformation mechanisms ( $\alpha$-lactose monohydrate, mannitol, sorbitol and pregelatinized maize starch) were processed with external lubrication on a rotary tablet press using different MgSt spraying rates (Jahn and Steffens, 2005). The concentration of the required MgSt concentration was reduced to $0.04 \%$ using external lubrication. In addition, no decrease in tensile strength was observed using different MgSt spraying rates (Jahn and Steffens, 2005). However, the collected data on externally lubricated tablets was not compared to internally lubricated tablets and no disintegration testing was performed in the study. While the potential of external lubrication has already been shown, none of the above studies thoroughly investigated the effect of external lubrication in comparison to internal lubrication using multiple formulations with different deformation mechanisms and evaluating the tablet tensile strength, tablet disintegration behaviour and ejection force during compaction. 
Therefore, the aim of current study was to investigate the impact of the process parameters of this external lubrication system implemented in a compaction simulator, on process and product quality, i.e. ejection force, tensile strength and disintegration time, using binary drug/filler formulations with different deformation mechanisms and lubrication needs. This is the first study where an automated external lubrication system was implemented in a compaction simulator. The results obtained by external lubrication, using MgSt as lubricant, were compared to those obtained by internal lubrication.

70 Furthermore, all raw materials and blends (non-lubricated and internally lubricated with MgSt) were characterized for wall friction angle (WFA) and compaction properties like specific work of compaction, elasticity, cohesion index and tablet brittleness index (TBI). Additionally, the concentration of MgSt in externally lubricated tablets was determined using inductively coupled plasma optical emission spectrometry (ICP-OES).

\section{Materials and methods}

\section{$2.1 \quad$ Materials}

Raw materials were selected based on their differences in lubrication requirement and deformation mechanism. Four common fillers were used in this study: microcrystalline cellulose (MCC) (Avicel ${ }^{\circledR}$ PH102, DuPont Pharma, Wilmington, DE, USA), lactose monohydrate (Tablettose ${ }^{\circledR}$ 80, Meggle, Wasserburg,

80 Germany), anhydrous dibasic calcium phosphate (DCP) (Emcompress ${ }^{\circledR}$ AN, JRS Pharma, Rosenberg, Germany) and mannitol (Pearlitol ${ }^{\circledR} 200$ SD, Roquette, Lestrem, France). Caffeine anhydrous (Siegfried PharmaChemikalien, Minden, Germany) and metoprolol tartrate micronized (MPT, Utag, Almere, The Netherlands) were used as model drug substances. Magnesium stearate (MgSt, Ligamed ${ }^{\circledR}$ MF-2-V, Peter Greven, Bad Münstereifel, Germany) was used as lubricant.

\subsection{Blend preparation}

Binary formulations consisted of $90 \%(w / w)$ filler and $10 \%(w / w)$ active pharmaceutical ingredient (API). Additionally, one placebo formulation, composed of $80 \%(w / w)$ mannitol and $20 \%(w / w)$ MCC, was included in the study. Prior to blending, caffeine and MPT were co-milled through a $1400 \mu \mathrm{m}$ screen to eliminate agglomerates (U5 Quadro Comil, Quadro, Waterloo, Canada). For all formulations, nonlubricated and internally lubricated blends were produced. The non-lubricated blends were used for the

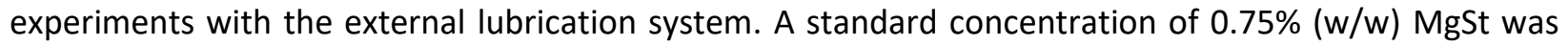
added to internally lubricated blends. However, a higher concentration of MgSt (1.25\%, w/w) was needed for formulations containing mannitol or lactose in combination with MPT and for the formulation containing mannitol combined with caffeine, as preliminary tests showed that blends with $0.75 \% \mathrm{MgSt}$ 
resulted in excessively high ejection forces. An overview of all blends can be found in Table 1 . The filler and API were blended for 15 minutes at 25 rotations per minute (rpm) in a tumbling mixer (Inversina Bioengineering, Wald, Switzerland). Subsequently, for the internally lubricated blends, $0.75 \%$ or $1.25 \%$ $(\mathrm{w} / \mathrm{w})$ MgSt was added and mixed for an additional 5 minutes at $15 \mathrm{rpm}$ or 10 minutes at $25 \mathrm{rpm}$, respectively.

\subsection{Tableting}

Tablets were produced on a STYL'One Evolution (Medelpharm, Beynost, France) compaction simulator. This compaction simulator was equipped with cylindrical flat faced Euro B punches of $10 \mathrm{~mm}$ diameter (Natoli Engineering Company, Saint Charles, MO, USA) and a single-paddle feeder with 6 fingers rotating clockwise. A compression profile emulating the Modul P rotary tablet press (GEA Pharma systems, Halle, Belgium) at a simulated turret speed of $40 \mathrm{rpm}$ was used. This profile was executed in displacement control with an upper punch penetration depth of $3.25 \mathrm{~mm}$. The compression thickness at pre and main compression was adapted per formulation to obtain the predefined compaction pressure.

All experiments were performed at 2 main compaction pressures (MCP), $65 \mathrm{MPa}$ and $255 \mathrm{MPa}$, while the pre-compaction pressure was fixed at $25 \mathrm{MPa}$. The ejection force overload limit was set at $2500 \mathrm{~N}$ with higher ejection forces resulting in a safety stop of the machine. Powder was poured into the feeder and the paddle of the feeder was rotated before starting the experiments to ensure the feeder was completely filled before starting the experiments. For all experiments, data was collected after reaching steady state conditions regarding the compaction pressure, tablet weight and ejection forces. For each experiment, 25 tablets were collected when reaching steady state conditions.

115 Tablet weight and overfill level were set at $325 \mathrm{mg}$ and $2 \mathrm{~mm}$, respectively, for formulations containing caffeine as API and the placebo formulation. As MPT-based formulations had inconsistent die filling, the tablet weight and overfill level were set at $250 \mathrm{mg}$ and $4 \mathrm{~mm}$, respectively.

A constant PS of $60 \mathrm{rpm}$ was applied for the external lubrication experiments of caffeine-based and placebo formulations, for the MPT-based formulations a PS of $300 \mathrm{rpm}$ was used. A higher PS was needed to ensure a consistent die filling for the MPT-based formulations which exhibited poor flowability. In contrast, for the experiments with internally lubricated blends, the effect of PS on the responses was also investigated as a higher PS could induce further mixing of the powder blends inside the feeder. Therefore, two PS were used for the experiments applying internal lubrication: $60 \mathrm{rpm}$ (PS1, corresponding to 20\% of the maximum PS) and $300 \mathrm{rpm}$ (PS2, corresponding to the maximum PS). 
125 An external lubrication system, designed by Medelpharm (Beynost, France), was implemented in the compaction simulator. This system consists of micro-dosing unit combined with a pulsed air blow cabinet generating a spray of lubricant based on the Venturi effect. The lubricant is transported through polyethylene tubings to the spraying nozzle which is attached to the feed shoe (Fig. 1). A double output for the spraying nozzle was designed to lubricate the upper punch as well as the lower punch and die wall.

130 Lubrication was applied before every die filling. The feeder moves until the spraying nozzle is located between the die opening and the upper punch. Next, the upper punch moves down to $25 \mathrm{~mm}$ above tabletop while the lower punch moves to the overfill position (Fig. 1). When the punches have reached their position, they remain stationary and the lubricant is sprayed.

In order to avoid contamination due to excessive MgSt in the feeder and tableting table, a built-in dust 135 extraction system was used during the experiments. The influence of two factors related to the external lubrication system on the process and product responses was evaluated: atomizing pressure and spraying time. While the atomizing pressure was varied at 3 levels (1, 3 and 5 bar), the spraying time was varied at 9 levels between 300 and 1000 ms (300, 325, 350, 375, 400, 425, 450, 500 and $1000 \mathrm{~ms})$. Due to the design of the external lubrication unit, the shortest spray time possible was $300 \mathrm{~ms}$. A non-lubricated experiment, i.e. spraying time of $0 \mathrm{~ms}$, was executed as a reference. Experiments were performed with increasing atomizing pressure and spraying time. This way, carry-over effects due to residual amounts of MgSt were minimized.

\subsection{Responses}

\subsubsection{Process responses}

\section{$145 \quad$ 2.4.1.1 Ejection force}

Ejection forces $(n=25)$ were recorded after reaching steady state conditions. The mean ejection force and corresponding standard deviation of each experiment were calculated for 25 tablets.

\subsubsection{Product responses}

\subsubsection{Tablet tensile strength}

150 The tablet breaking force $(n=10)$ was determined using a hardness tester (SmartTest 50, Sotax, Basel, Switzerland). Tablet diametrical tensile strength (MPa) was calculated according to Eq. (1) (Fell and Newton, 1970):

Tablet tensile strength $(\mathrm{MPa})=\frac{2 \mathrm{~F}}{\pi \mathrm{dt}}$ 
where $\mathrm{F}$ is the breaking force $(\mathrm{N})$, $d$ tablet diameter $(\mathrm{mm})$ and $\mathrm{t}$ tablet thickness $(\mathrm{mm})$. Using the tensile

155 strength instead of hardness, tablets of different sizes and shapes can be compared with each other.

\subsubsection{Disintegration time}

Tablet disintegration time (s) was measured for six tablets of each experiment using distilled water at 37.0 $\pm 2{ }^{\circ} \mathrm{C}$ as medium. The disintegration test (DIST-3, PharmaTest, Hainburg, Germany) was conducted as described in the European Pharmacopoeia. The disintegration time was defined as the time when no remains or only a residue of soft mass can be observed on the screen (European Directorate for the Quality of Medicine, 2019a).

\subsubsection{Magnesium stearate (MgSt) concentration}

ICP-OES was used to determine the amount of MgSt in externally lubricated tablets $(n=5)$. Sample preparation of the tablets consisted of an acid digestion, by addition of $1 \mathrm{~mL} 37 \%$ hydrogen chloride

165 (Sigma-Aldrich, Diegem, Belgium) and $7 \mathrm{~mL}$ 65\% nitric acid (Sigma-Aldrich), followed by microwave digestion for $20 \mathrm{~min}$ at $180^{\circ} \mathrm{C}$ (MARS 6, CEM, Matthews, NC, USA). Next, the magnesium concentration of the obtained solution was measured via ICP-OES (Varian Vista MPX, Varian, Palo Alto, CA, USA). The absorbance of samples and calibration standard solutions (Merck, Darmstadt, Germany) were measured at a wavelength of $280.270 \mathrm{~nm}$. Using the calibration curve and the molecular weights of magnesium and

$170 \mathrm{MgSt}$, the amount of MgSt in externally lubricated tablets could be calculated. The limit of quantification was defined as 10 times the standard deviation of a blank. The data were normalised for the tablet weight.

\subsection{Raw material and blend characterization}

\subsubsection{Wall friction angle (WFA)}

A ring shear tester (Type RST-XS, Dietmar Schulze Schüttgutmesstechnik, Wolfenbüttel, Germany) was used to determine the WFA $(n=3)$ which is defined as the friction between the powder sample and the wall material sample (Schulze et al., 2008). This was determined using a XS-WL shear cell with spacer rings and wall material sample (316 stainless steel bottom plate with surface roughness Ra of $0.28 \mu \mathrm{m}$ ). The WFA was measured under 5 different wall normal stresses, 4000, 3280, 2560, 1840, 1120 and $400 \mathrm{~Pa}$. The resulting wall yield loci were used to calculate the WFA (European Directorate for the Quality of Medicine, 2019b; Schulze et al., 2008; Van Snick et al., 2018a) 


\subsubsection{Compaction properties}

\subsubsection{1 "In-die" compaction properties}

Three phases can be distinguished in the compression cycle of a tablet. These phases are visualized in the force-displacement curve plotting compaction pressure against punch separation (Fig. 2). The first step includes powder particle rearrangement and packing $\left(A^{\prime}-A\right)$ as the punches move towards each other. In the second phase $(A-B)$, the compaction pressure increases until a maximal pressure (B) with a corresponding minimal punch separation (D). During this phase, fragmentation and/or plastic deformation of the powder particles occur. The applied pressure is released in the third phase (B-C) called decompression or unloading, resulting in an elastic recovery of the compact (C-B-D) (Busignies et al., 2004; Grymonpré et al., 2017; Michaut et al., 2010; Pontier et al., 2002; Vachon and Chulia, 1999).

The energy of each phase can be calculated from the area under the curve. The work of compression or the total energy $(A B D)$ can be determined from the integral calculus from $A$ to $D$, while the work of elastic recovery $(B C D)$ is calculated by integration from $C$ to $D$ (Fig. 2). The difference between the work of compression and work of elastic recovery is defined as the work of compaction or the net energy (ABC)

195 (Fig. 2). The work of compaction expresses the energy needed to form a compact. In order to compare between different tablets, the values of the work of compaction are divided by the tablet weight, yielding a specific work of compaction (Eq. (2) (Grymonpré et al., 2017; Vachon and Chulia, 1999). The degree of elasticity was calculated using Eq. (3). The cohesion index, defined as the ratio of tensile strength and work of compaction, was used to express the bonding strength of a compact (Eq. (4)) (Delacourte et al., 1993; Vachon and Chulia, 1999).

$$
\begin{aligned}
& \text { Specific work of compaction }\left(\frac{J}{\mathrm{~g}}\right)=\frac{\text { Work of compaction }}{\text { Tablet weight }} \\
& \text { Elasticity }(\%)=\frac{\text { Work of elastic recovery }}{\text { Work of compression }} \\
& \text { Cohesion index }\left(\frac{\mathrm{MPa}}{\mathrm{J}}\right)=\frac{\text { Tensile strength }}{\text { Work of compaction }}
\end{aligned}
$$

To determine the compaction properties of the raw materials and blends, powder ( $n=10,400 \pm 10 \mathrm{mg}$ ) was individually weighed, manually filled into the die and compacted at an MCP of $191 \mathrm{MPa}$ without a pre-compaction step at low tableting speed. External lubrication was applied to minimize confounding of the results due to friction. A spraying time of $500 \mathrm{~ms}$ and an atomizing pressure of 3 bar were used as settings for the external lubrication system. 


\subsubsection{2 "Out-of-die" compaction properties}

210 For the determination of tablet brittleness index (TBI) ( $n=5)$, a texture analyser (TA.XTplusC Texture Analyser, Stable Micro Systems, Godalming, UK) was used, equipped with a $50 \mathrm{~kg}$ load cell. TBI was calculated using Eq. (5) (Paul and Sun, 2017):

$$
\mathrm{TBI}=\frac{1}{\text { Maximum elastic strain }}=\frac{\text { Tablet diameter }}{\text { Maximum elastic deformation }}
$$

The maximum elastic deformation was calculated from the force-displacement curve of the diametrical tablet breaking test, using the first derivative method (Gong and Sun, 2015). The tablets produced as described in Section 2.5.2.1. were used for the determination of TBI. The data analysis was performed using an in-house developed Python script (Van Rossum and Drake Jr, 1995).

\section{Results and discussion}

\subsection{Raw material and blend characterization}

$220 \quad 3.1 .1$ Wall friction angle (WFA)

MPT $\left(34.6^{\circ}\right)$ and mannitol $\left(19.6^{\circ}\right)$ showed the highest WFA among all raw materials in the study (Table 2 ). Regarding the fillers, the lowest WFA was observed for MCC $\left(9.9^{\circ}\right)$ followed by DCP $\left(13.1^{\circ}\right)$, lactose $\left(16.1^{\circ}\right)$ and mannitol $\left(19.6^{\circ}\right)$. Caffeine exhibited a lower WFA $\left(17.4^{\circ}\right)$ compared to MPT. As expected, a low WFA was measured for MgSt $\left(8.7^{\circ}\right)$ explaining the ability of MgSt in reducing the ejection forces.

225 Similar trends could be observed concerning the WFA of the blends (Fig. 3). Non-lubricated blends containing MCC gave the lowest WFA, while mannitol-based formulations exhibited the highest WFA. Additionally, the WFA of MPT-based blends was higher compared to the corresponding caffeine-based blends, both for non-lubricated and internally lubricated blends. While the addition of MgSt in caffeinebased formulations resulted in a significant decrease in WFA, the decrease in WFA for MPT-based blends

230 appeared to be less affected by MgSt. Within the MPT-based formulations, the WFA of mannitol-MPT and DCP-MPT was almost unchanged for internally lubricated blends compared to non-lubricated blends. Thus, MPT-based formulations appeared to be less affected by the internal blending of MgSt, possibly due to the high specific surface area of MPT as previously described by Van Snick et al. (2018b).

\subsubsection{Compaction properties}

\section{3.1.2.1 "In-die" compaction properties}

Three compaction properties were derived from the force-displacement curves. The specific work of compaction defines the energy used for plastic deformation and fragmentation, while the elasticity 
represents the elastic recovery of the compact during decompression. The ratio of specific work of compaction to tensile strength is defined as the cohesion index and describes the bonding properties of the compact.

The specific work of compaction and cohesion index of the pure fillers followed the order: MCC > mannitol $>$ lactose $\approx$ DCP (Table 2). Caffeine and MPT showed similar values for the specific work of compaction which were higher than lactose and DCP but lower than mannitol. Regarding the cohesion index, caffeine showed a similar cohesion index compared to mannitol. MgSt gave the lowest value of specific work of compaction of all raw materials. While the elasticity was below $5 \%$ and $8 \%$ for the fillers and APIs, respectively, an elasticity of almost $30 \%$ was observed for MgSt (Table 2). This explains the low specific work of compaction for MgSt as a significant part of energy is lost due to elastic recovery during unloading. The cohesion index of MPT and MgSt could not be determined as these materials resulted in poor quality tablets (lamination, chipping). It can be assumed that these materials would have a low cohesion index.

250 The specific work of compaction and elasticity of the blends correlated well with the values of the raw materials as the blends only contained 10\% API (Supplementary data Table S1). Similar values of the specific work of compaction and elasticity of blends were observed independent of the included API. For MCC-containing blends, a lower cohesion index was observed for MPT compared to caffeine (Table S1). This can be explained by the lower cohesion index of MPT and the lower tensile strength of MCC-MPT 255 tablets compared to MCC-caffeine tablets. For other fillers, the effect of MPT on the cohesion index was less pronounced, probably due to a different deformation mechanism. While MCC deforms plastically, the other fillers (lactose, DCP and mannitol) all showed to a certain extent fragmentary behaviour (Paul and Sun, 2017). In general, internal lubrication resulted in a lower specific work of compaction, higher elasticity and lower cohesion index compared to the non-lubricated blends. A higher amount of MgSt, i.e.

$2601.25 \%$, further enhanced these effects. These findings are in accordance with the raw material characteristics of MgSt which exhibits a low specific work of compaction and a high elasticity. The lower cohesion index of lubricated blends can be attributed to a stronger decrease in tensile strength due to the addition of MgSt in comparison with the decrease in specific work of compaction. The effect of the internal blending of MgSt on the cohesion index was most notable for MCC blends while DCP blends appeared to

265 be least affected. As MCC is known to deform plastically while DCP is a brittle material, the decrease in tensile strength when MgSt is added is larger for MCC compared to DCP (Bolhuis et al., 1985; Bolhuis and Hölzer, 2011; Vromans and Lerk, 1988). Moreover, for lactose-based formulations, a strong decrease in cohesion index is observed when MgSt is added, even more pronounced for the lactose-caffeine 
formulation. Although lactose and DCP have similar cohesion indices as raw materials and non-lubricated

270 blends, lactose appeared to be more affected by MgSt. The same trend can also be observed on the TBI where MgSt affected lactose-based blends more compared to DCP-based formulations (Section 3.1.2.2).

In conclusion, the internal blending of MgSt increased the elasticity while lowering the specific work of compaction and cohesion index. Strong elastic recovery should be avoided as this could break the formed inter-particle bonds, resulting in a lower tensile strength but also tablet defects like capping (Busignies et

275 al., 2004; Grymonpré et al., 2017). As external lubrication involves no internal blending of the lubricant, these negative effects could be avoided.

\subsubsection{2 "Out-of-die" compaction properties}

$\mathrm{TBI}$ is an important material property as it assesses the fragmentation and deformation behaviour of tablets. A high brittleness can result in a higher tablet friability and tablet defects like chipping, capping and lamination. Additionally, tablet tensile strength, porosity and lubrication are known to be affected by TBI (Paul and Sun, 2017).

The following order was obtained for TBI of the raw materials: $\mathrm{MCC}<$ mannitol $<$ caffeine $<$ lactose $=\mathrm{DCP}$ (Table 4). There observations are in accordance with the literature describing the plastically deforming behaviour of MCC while lactose and DCP are classified as brittle materials (Paul and Sun, 2017). The TBI

285 of MPT and MgSt could not be determined as compression of these materials resulted in defected tablets (capping, lamination, chipping).

In accordance with the raw materials, MCC-based formulations resulted in tablets with the lowest TBI while lactose-containing blends showed the highest TBI (Table S1). Although lactose and DCP had a similar TBI as raw materials, TBI was higher for lactose-formulations compared to DCP-formulations. Possibly, a combination of the smaller particle size of lactose compared to DCP could explain the higher sensitivity of lactose-based formulations. API addition to a formulation increased TBI compared to the raw materials, this effect was most pronounced for MPT. TBI increased for the internally lubricated blends in comparison with the non-lubricated blends. Additionally, a higher MgSt concentration increased the TBI. This was in accordance with earlier studies and can be linked to a reduction in particle interactions and bond

295 formation due to the presence of MgSt (Paul and Sun, 2017). As internal lubrication is associated with a higher TBI which increases the risk of having tablet defects and high tablet friability, external lubrication could be a good alternative as these negative effects are minimized using this method. 


\subsection{MgSt concentrations and reproducibility of the external lubrication system}

Experiments were performed on the formulation containing mannitol-MCC (MCP $65 \mathrm{MPa}$ ) to find an adequate spraying time to study the reproducibility of the external lubrication system. For all atomizing pressures, the cut-off spraying time was defined as the spraying time point corresponding to a drastic decrease in ejection forces (Section 3.3). MgSt concentrations were determined at 5 testing points: $0 \mathrm{~ms}$ (no lubrication), at the cut-off spraying time, $10 \mathrm{~ms}$ before and $20 \mathrm{~ms}$ after the cut-off spraying time (to have data on MgSt amounts prayed as close to the cut-off time as possible), and at $500 \mathrm{~ms}$ (to obtain a well-lubricated sample). These MgSt concentrations in function of spraying time for mannitol-MCC are shown in Figure 4. Non-lubricated tablets and externally lubricated tablets produced at spraying times below the cut-off value resulted in MgSt concentrations below limit of quantification of the ICP-OES method. From this set of tests, $500 \mathrm{~ms}$ was selected as the most suitable spraying time to test tablet-totablet variation of MgSt concentrations as this spraying time gave adequate lubrication of all formulations, i.e. low ejection forces, and allowed for accurate determination of MgSt concentrations.

In order to gain more knowledge about the system performance and concentration of MgSt when low ejection forces are reached, externally lubricated tablets containing MCC-MPT, lactose-caffeine, mannitolcaffeine and mannitol-MCC (MCP $65 \mathrm{MPa}$ ) were analysed. Tablets were produced at 1, 3 and 5 bar atomizing pressure and a constant spraying time of $500 \mathrm{~ms}$. Concentrations between 0.01 and $0.06 \% \mathrm{MgSt}$ were found, corresponding to levels of $0.05 \mathrm{mg}$ and $0.20 \mathrm{mg} \mathrm{MgSt}$ per tablet (Fig. 5). Thus, these concentrations were $1-10 \%$ that of internally lubricated tablets with $0.75 \%$ MgSt. No significant effect of atomizing pressure on the concentrations was observed.

The reproducibility of the external lubrication system was evaluated by determining the variability of the MgSt concentration within one run. Therefore, 25 consecutive produced tablets were analysed (Fig. 6). For this purpose, externally lubricated tablets consisting of lactose-caffeine were produced using a spraying time of $500 \mathrm{~ms}$ and an atomizing pressure of 5 bar. The mean concentration was $0.04 \pm 0.01 \%$ MgSt (0.13 $\pm 0.02 \mathrm{mg} \mathrm{MgSt} \mathrm{per} \mathrm{tablet).} \mathrm{When} \mathrm{plotting} \mathrm{the} \mathrm{individual} \mathrm{ejection} \mathrm{forces} \mathrm{(151} \pm 8 \mathrm{~N})$, no correlation was noticed as the difference between the lowest value and highest value of the ejection forces is only $25 \mathrm{~N}$ (Fig. 6). The MgSt concentrations between the tested formulations indicated 325 reproducible lubrication at the investigated settings. In Sections 3.3-3.5, the effect of spraying time and atomizing pressure, which is linked to the MgSt concentrations, will be discussed. When the cut-off spraying time is reached, no additional effect of spraying time can be observed on the ejection force, tensile strength and disintegration time (Sections 3.3-3.5). These results demonstrate the reproducibility 
of the external lubrication system implemented in the compaction simulator and its effect on the studied responses.

\subsection{Ejection force}

The non-lubricated and internally lubricated blends consisting of DCP-MPT could not be processed on the compaction simulator due to feeder blockage, most probably due to the combined effect of the high density of DCP and poor flowability of MPT.

335 The ejection forces of the experiments can be found in the supplementary date (Table S2). Overall, MCCbased formulations yielded the lowest ejection forces when using non-lubricated blends, followed by DCPbased formulations. In contrast, lactose- and mannitol-based formulations yielded the highest ejection forces. This is in accordance with the WFA of the raw materials and blends (Section 3.1). The inclusion of MPT into all formulations increased the ejection forces during tableting with internal lubrication or without lubrication. These observations are in accordance with the WFA experiments which indicated that MPT exhibited by far the highest WFA of all tested materials. It should be noted that the tablet weight of MPT-based formulations was lower compared to caffeine-based formulations. This signifies that if the tablet weight of MPT-based formulations would be similar to the tablet weight of caffeine-based formulations, the ejection forces of MPT-formulations without lubrication or with internal lubrication could be even higher. Moreover, extensive sticking to tablet tooling was observed for mannitol- and MPTbased formulations, contributing to these high ejection forces. As the ejection forces of non-lubricated and internally formulations correlated well with the corresponding WFAs, WFA can be considered predictive for ejection issues during tableting.

Non-lubricated experiments could be performed for MCC-based formulations (MCP 65 and $255 \mathrm{MPa}$ ), lactose-caffeine (MCP 65 and $255 \mathrm{MPa}$ ), mannitol-caffeine (MCP $65 \mathrm{MPa}$ ) and mannitol-MCC (MCP 65 MPa). While external lubrication could be applied for all formulations, internally lubricated blends with $0.75 \% \mathrm{MgSt}$ containing lactose and/or mannitol in combination with MPT could not be processed due to excessively high ejection forces, i.e. higher than the ejection force overload limit (>2500 N). Using a higher concentration of lubricant, i.e. $1.25 \% \mathrm{MgSt}$, tablets could only be produced when compacted at the lowest MCP. Moreover, ejection forces of these internally lubricated tablets exceeded the minimal values obtained by external lubrication. For the formulation containing mannitol as a combination with caffeine, a higher concentration of MgSt (1.25\% MgSt) was needed for the highest MCP as ejection forces over $1000 \mathrm{~N}$ were observed using $0.75 \% \mathrm{MgSt}$. 
Evaluating the ejection forces of externally lubricated tablets in function of the spraying time, it can be seen that similar ejection forces were obtained when no lubrication or external lubrication at low spraying times was applied, independent of the atomizing pressure (Fig. 7). When prolonging the spraying time, a sudden drop in ejection forces was observed. The time point corresponding to the drastic decrease in ejection forces is defined as the cut-off spraying time. For most experiments, the cut-off spraying time was situated between 325 and 400 ms and depended on the atomizing pressure. Using a higher atomizing pressure, the drop in ejection forces occurred at a lower spraying time, which is attributed to a better dispersion of MgSt at a higher atomizing pressure. In case of ejection force overload during experiments without lubrication, external lubrication could only be applied at relatively high spraying times (i.e. above the cut-off spraying time). This trend proved to be independent of MCP and formulation. These findings can be explained by the external lubrication mechanism: at a specific spray time, the number of MgSt particles is sufficient to create a film on the tooling, resulting in less friction and lower ejection forces.

Ejection forces after the cut-off spray time were slightly higher using an atomizing pressure of 1 bar, compared to the other atomizing pressures, i.e. 3 and 5 bar, for formulations containing mannitol and/or MPT. Moreover, the cut-off of these formulations was situated at a slightly higher spraying time ( $>400$ $\mathrm{ms}$ ). Similarly, the mannitol-and/or MPT-based formulations exhibited high WFAs and high ejection forces 375 when tableting without lubrication (or could not be tableted at all). Thus, a higher amount of lubricant was needed to lower the ejection forces for these formulations. These findings suggest that the amount of MgSt sprayed when the atomizing pressure is set on 1 bar was too low to sufficiently layer the tooling and thus reduce sticking and ejection forces. For all other formulations, the applied atomizing pressure did not affect the ejection forces at spraying times before the cut-off value (375-400 ms). A further 380 increase in the spraying time after the cut-off, i.e. from 500 to $1000 \mathrm{~ms}$, did not affect the ejection forces. As the surface of punches and die wall is already sufficiently covered with MgSt at the cut-off spraying time, deposition additional MgSt could not further decrease friction.

Although low ejection forces (250-100 N) for MCC-caffeine were already observed without lubrication, external lubrication further decreased the ejection forces (50-100 N). Although for MCC-MPT the non385 lubricating ejection forces were higher (650-500 N), similar ejection forces were obtained with external lubrication, applying 3 or 5 bar (Fig. 8). Using internal lubrication, equal ejection forces were observed for MCC-caffeine compared to external lubrication, while higher values were recorded for internally lubricated MCC-MPT. 
Compared to non-lubricated experiments, ejection forces reduced from 500 to 100-150 N (MCP 65 MPa)

390 and from 2000 to 300-350 N (MCP $255 \mathrm{MPa}$ ) using external lubrication with spraying times above the cutoff value for lactose-caffeine (Fig. 8). Applying internal lubrication, similar ejection forces were recorded as those obtained by external lubrication.

Compression of the lactose-MPT formulation without lubrication resulted in an ejection force overload. Using external lubrication, ejection forces were drastically lowered, while internal lubrication resulted in high ejection forces (600-1000 N at MCP 65 MPa) and ejection force overload (MCP $255 \mathrm{MPa}$ ).

For DCP-caffeine, ejection forces were halved to $100 \mathrm{~N}$ (MCP $65 \mathrm{MPa}$ ) and $300 \mathrm{~N}$ (MCP $255 \mathrm{MPa}$ ) using external lubrication in comparison with non-lubricated experiments (Fig. 8). Similar ejection forces were recorded for internal and external lubrication.

The lowest ejection forces of the mannitol-based formulations were observed for mannitol-MCC, followed 400 by mannitol-caffeine, while ejection forces were much higher for mannitol-MPT. As a result, internal lubrication could not be applied for mannitol-MPT, while mannitol-MCC and mannitol-caffeine could be processed using internal lubrication. Applying external lubrication, all formulations could be processed. For mannitol-MPT (MCP $65 \mathrm{MPa}$ ), no lubrication resulted in an ejection force overload while external lubrication using spraying times below the cut-off value was possible although high ejection forces (>2000

405 N) were observed (Fig. 8). Ejection forces were drastically lowered after the cut-off value, reaching levels of 100-150 N. For mannitol-MPT tablets compacted at $255 \mathrm{MPa}$, high ejection forces were still observed using higher spraying times.

For internal lubrication, the effect of higher PS on the ejection forces was limited for most formulations. For MPT-based formulations, even a slight increase in the ejection forces was observed. This was 410 attributed to densification of the blend inside the feeder at higher PS. Therefore, a smaller fill depth was used than at lower PS to maintain the same tablet weight. Consequently, a smaller fraction of the compaction pressure is needed to densify the powder into a tablet, and thus, a slightly larger fraction could be transferred radially causing higher ejection forces. In addition, better mixing of MPT could increase the already high ejection forces.

415 Increasing the MCP resulted in higher ejection forces as a result of the higher friction and residual die-wall pressure. However, for MCC-based formulations, the opposite effect was observed: lower ejection forces were observed at $255 \mathrm{MPa}$ compared to $65 \mathrm{MPa}$, for both APIs and all lubrication methods (no lubrication, external and internal lubrication). Remarkably, for MCC-based tablets produced at low and high MCP, the 
tablet diameters after ejection were larger $(10.04 \mathrm{~mm})$ and smaller $(9.99 \mathrm{~mm})$, respectively, than the die

420 diameter $(10.00 \mathrm{~mm})$, while other the tablet diameters of other formulations ranged from 10.02 to 10.10 $\mathrm{mm}$. Although this change in diameter of MCC-based tablets at higher MCP was unexpected, the inverse correlation between MCP and ejection force seems linked to this observation.

\subsection{Tensile strength}

An overview of the tensile strength of the experiments can be found in the supplementary date (Table 425 S3). External lubrication did not affect the tablet tensile strength as no decrease in tensile strength was observed compared to non-lubricated tablets. This effect can be explained by the absence of MgSt inside the formulation, which is consequently not interfering with particle bonding formation during compaction. No negative effect of the parameters of the external lubrication system, atomizing pressure and spraying time, were observed on the tensile strength (Fig. 8). In contrast, when applying internal

430 lubrication, a decrease in tensile strength was observed in some cases. The effect of internal lubrication was most pronounced for the MCC-based formulations as the tensile strength of internally lubricated MCC-based tablets was significantly lower compared to tablets produced via external lubrication or without lubrication (Fig. 8). This is in agreement with literature as plastically deforming materials are known to be most sensitive to the effects of the internal blending of MgSt (Bolhuis et al., 1985; Bolhuis

435 and Hölzer, 2011; Vromans and Lerk, 1988). The plastically deforming behaviour of MCC was confirmed by the high specific work of compaction and low TBI (Section 3.1).

In contrast, the tensile strength of DCP-caffeine tablets appeared to be unaffected by internal lubrication (Fig. 8). This lubricant insensitivity of DCP can be attributed to its brittle behaviour which was confirmed by the high TBI and the low specific work of compaction (Section 3.1).

440 For lactose-based formulations, a lower tensile strength was observed for internally lubricated tablets compared to externally lubricated tablets (Fig. 8). Although pure DCP and lactose showed similar values of specific work of compaction and TBI, a strong decrease in cohesion index was observed for lactosebased formulations when MgSt is added compared to DCP-based formulations. (Section 3.1).

The same trend, lower tensile strength when applying internal lubrication, was noticed for mannitol-based 445 tablets (Fig. 8). This can be attributed to a combination of lubricant sensitivity and the high ejection forces recorded during compression of internally lubricated tablets. During ejection, these high ejection forces will cause more stress which will damage the formed inter-particle bonds in the tablet when this stress is released. This will not only reduce the tensile strength, but also result in tablet defects such as damages 
to the tablet band, and in more severe cases chipping, capping or lamination. A higher concentration of 450 MgSt resulted in a better lubrication which was beneficial for the tablet quality. Therefore, tensile strength was not further lowered when increasing the amount of MgSt to $1.25 \%$ for mannitol-caffeine.

As previously mentioned in this section, similar tensile strengths were generally obtained for nonlubricated and externally lubricated tablets. However, for lactose-caffeine (MCP $255 \mathrm{MPa}$ ), mannitolcaffeine (MCP $65 \mathrm{MPa}$ ), mannitol-MCC (MCP $65 \mathrm{MPa}$ ), lower tensile strengths were observed for non-

455 lubricated tablets and externally lubricated tablets produced with low spraying times compared to higher spraying times (Fig. 8). This can be explained by the higher ejection forces (1500-2000 N) of those formulations when not properly lubricated. A lower tensile strength, chipping and defects to the tablet band were observed due to the high ejection forces resulting in a lower tensile strength. At lower spraying times, no effect of the external lubrication on the ejection forces was observed. When using longer spraying times, the ejection forces dropped and subsequently, tensile strength increased (Fig. 8).

The most significant effect of PS on the tensile strength when applying internal lubrication was observed for MCC-based formulations (Fig. 8). A higher PS reduced the tensile strength which is attributed to the plastically deforming behaviour of MCC. The lubricant sensitivity of MCC tablets in function of PS in the feed frame of a rotary tablet press was already observed by Peeters et al. (2016). For internally lubricated

465 blends containing lactose or mannitol, a limited effect of PS was noticeable on the tensile strength, while DCP was not susceptible to MgSt due to its brittle behaviour (Fig. 8).

As expected, tensile strength increased at higher MCP. Regarding the fillers, MCC-based formulations tablet yielded tablets with the highest tensile strength followed by mannitol, while DCP and lactose resulted in tablets with the lowest tensile strength. These observations are in agreement with the specific 470 work of compaction and TBI (Section 3.1). Inclusion of caffeine into the formulations resulted in higher tensile strengths compared to MPT, which can be explained by higher ejection forces, higher TBI and increased elasticity of MPT resulting in tablet defects. This effect was most noticeable with the MCC-based formulations due to the highest tensile strengths of these formulations.

\subsection{Disintegration time}

475 An overview of the disintegration of all experiments can be found in the supplementary date (Table S4). Externally lubricated tablets did not exhibit longer disintegration times compared to non-lubricated tablets due to the very small amounts of MgSt present in externally lubricated tablets (Figs. 4, 5). No negative effect of the parameters, atomizing pressure and spraying time, of the external lubrication 
system was observed (Fig. 8). In contrast, for most formulations, disintegration time was prolonged when using internal lubrication (Fig. 8).

While the tensile strength of DCP-caffeine tablets was unaffected by the internal blending of MgSt, the disintegration was increased by a factor 4 compared to non-lubricated and externally lubricated tablets (Fig. 8). The same effect was observed for lactose- and mannitol-based formulations (Fig. 8).

For MCC-caffeine, similar disintegration times were recorded for all lubrication methods. Moreover, fast disintegration (<2-3 min) was observed for both MCPs (Fig. 8). The opposite effect was observed for MCCMPT tablets where a shorter disintegration was observed for internally lubricated tablets compared to non-lubricated and externally lubricated tablets. This decrease was most visible for tablets compacted at $255 \mathrm{MPa}$ and can be explained by the interaction between tensile strength and disintegration. As internally lubricated tablets showed a lower tensile strength compared to non-lubricated and externally lubricated tablets, this resulted in faster tablet disintegration.

In addition, an interaction between ejection forces, tensile strength and disintegration was observed for externally lubricated tablets based of mannitol-MPT tablets (65 MPa) (Fig. 8). As short spraying times of the external lubrication system resulted in higher ejection forces, a lower tensile strength was obtained due to tablet defects (Sections 3.3 and 3.4) As a result, faster disintegration occurred. When increasing the spraying time, ejection forces dropped and a better tablet quality was obtained, resulting in slower disintegration.

A higher PS of the forced feeder for the internally lubricated blends led to a prolonged disintegration for some formulations as a better distribution of the hydrophobic MgSt inside the feeder can occur due to the mixing effect in the paddle feeder. This effect was visible for DCP-caffeine (MCP $65 \mathrm{MPa}$ ), lactosecaffeine (MCP 65 and $255 \mathrm{MPa}$ ), mannitol-caffeine (MCP 65 and $255 \mathrm{MPa}$ ) and mannitol-MCC (MCP 255 MPa) (Fig. 8). A limited effect of PS was observed on disintegration caused by very short disintegration times for MCC-caffeine, MCC-MPT and mannitol-MCC (MCP 65 MPa) (Fig. 8). The opposite effect was observed for MCC-caffeine and MCC-MPT tablets (MCP $255 \mathrm{MPa}$ ) where faster disintegration was recorded when using a higher PS, caused by the lower tensile strength of tablets (Section 3.4).

505 The effect of a higher concentration of MgSt, from $0.75 \%$ to $1.25 \%$, on the disintegration was studied for mannitol-caffeine. An increase of the MgSt concentration further prolonged the disintegration time which was even more pronounced at higher PS. 


\section{Conclusion}

This study evaluated the performance of an external lubrication system implemented in a compaction

510 simulator. Low ejection forces were obtained with a much lower lubricant concentration (0.01-0.06\% MgSt) compared to internal lubrication ( $0.75 \%$ and/or $1.25 \% \mathrm{MgSt}$ ). In addition, externally lubricated tablets showed no reduced tensile strength and no prolonged disintegration times, which is in contrast to internal lubrication. Furthermore, the effect of internal versus external lubrication on tensile strength could be correlated to the different deformation mechanisms of the formulations. A reduced tensile 515 strength was observed for internally lubricated formulations containing a plastically deforming material (MCC) compared to non-lubricated and externally lubricated blends whereas formulations with brittle materials (DCP) showed equal tensile strength independent of the lubrication method. It was shown that internal lubrication increased the elasticity and tablet brittleness and reduced the specific work of compaction and cohesion index. Using external lubrication, these negative effects are minimized. As external lubrication proved highly valuable for lubricant-sensitive formulations, further research could focus on the upscaling of the external lubrication system to a rotary tablet press.

\section{Acknowledgments}

This research was financially supported by the FWO Flanders (grant: 1S88518N). The authors acknowledge the co-workers of Medelpharm for their scientific input and JRS for providing the DCP samples. 


\section{References}

Bolhuis, G.K., Hölzer, A.W., 2011. Lubrication issues in direct compaction, in: Pharmaceutical Powder Technology. Informa Healthcare USA Inc., New York, pp. 205-234.

Bolhuis, G.K., Lerk, C.F., Zijlstra, H.T., De Boer, A.H., 1975. Film formation by magnesium stearate during mixing and its effect on tabletting. Pharm. Weekbl. 110, 317-325.

Bolhuis, G.K., Reichman, G., Lerk, C.F., Kamp, H.V. Van, Zuurman, K., 1985. Evaluation of anhydrous $\alpha-$ lactose, a new excipient in direct compression. Drug Dev. Ind. Pharm. 11, 1657-1681.

Bolhuis, G.K., Smallenbroek, A.J., Lerk, C.F., 1981. Interaction of tablet disintegrants and magnesium stearate during mixing I: Effect on tablet disintegration. J. Pharm. Sci. 70, 1328-1330. https://doi.org/10.1002/jps.2600701210

Busignies, V., Tchoreloff, P., Leclerc, B., Besnard, M., Couarraze, G., 2004. Compaction of crystallographic forms of pharmaceutical granular lactoses. I. Compressibility. Eur. J. Pharm. Biopharm. 58, 569-576. https://doi.org/10.1016/j.ejpb.2004.04.007

Chen, H., Aburub, A., Sun, C.C., 2019. Direct Compression Tablet Containing 99\% Active Ingredient-A Tale of Spherical Crystallization. J. Pharm. Sci. 108, 1396-1400. https://doi.org/10.1016/j.xphs.2018.11.015

Delacourte, A., Predella, P., Leterme, P., Provasi, D., Colombo, P., Conte, U., Catellani, P.L., Guyot, J.C., 1993. A method for quantitative evaluation of the effectiveness of tee lubricants used in tablet technology. Drug Dev. Ind. Pharm. 19, 1047-1060. https://doi.org/10.3109/03639049309063000

Dun, J., Osei-Yeboah, F., Boulas, P., Lin, Y., Sun, C.C., 2020. A systematic evaluation of poloxamers as tablet lubricants. Int. J. Pharm. 576, 118994. https://doi.org/10.1016/j.ijpharm.2019.118994

European Directorate for the Quality of Medicine, 2019a. 2.9.1. Disintegration of Tablets and Capsules. Eur. Pharmacopoeia 10.0.

European Directorate for the Quality of Medicine, 2019b. 2.9.36. Powder flow. Eur. Pharmacop. 10.0.

Fell, J.T., Newton, J.M., 1970. Determination of tablet strength by the diametral-compression test. J. Pharm. Sci. 59, 688-691. https://doi.org/10.1002/jps.2600590523

Gong, X., Sun, C.C., 2015. A new tablet brittleness index. Eur. J. Pharm. Biopharm. https://doi.org/10.1016/j.ejpb.2015.04.007

Grymonpré, W., Verstraete, G., Van Bockstal, P.J., Van Renterghem, J., Rombouts, P., De Beer, T., Remon, J.P., Vervaet, C., 2017. In-line monitoring of compaction properties on a rotary tablet press during tablet manufacturing of hot-melt extruded amorphous solid dispersions. Int. J. Pharm. 517, 348358. https://doi.org/10.1016/j.ijpharm.2016.12.033

Jahn, T., Steffens, K.J., 2005. Press chamber coating as external lubrication for high speed rotary presses: Lubricant spray rate optimization. Drug Dev. Ind. Pharm. 31, 951-957. https://doi.org/10.1080/03639040500306161

Kamiya, T., Kondo, H., Hiroma, H., Yamashita, K., Hakomori, T., Sako, K., Iwao, Y., Noguchi, S., Itai, S., 2016. Impact of process parameters on Mg-St content and tablet surface wettability in the external 
lubrication method for a rotary tablet press. Adv. Powder Technol. 27, 193-198. https://doi.org/10.1016/j.apt.2015.11.012

Kondo, H., Toyota, H., Kamiya, T., Yamashita, K., Hakomori, T., Imoto, J., Kimura, S. ichiro, Iwao, Y., Itai, S., 2017. Effect of the external lubrication method for a rotary tablet press on the adhesion of the film coating layer. Chem. Pharm. Bull. 65, 847-853. https://doi.org/10.1248/cpb.c17-00376

Lerk, C.F., Bolhuis, G.K., Smallenbroek, A.J., Zuurman, K., 1982. Interaction of tablet disintegrants and magnesium stearate during mixing. II. Effect on dissolution rate. Pharm. Acta Helv. 57, 282-286.

Li, J., Wu, Y., 2014. Lubricants in pharmaceutical solid dosage forms. Lubricants 2, 21-43. https://doi.org/10.3390/lubricants2010021

Michaut, F., Busignies, V., Fouquereau, C., Huet De Barochez, B., Leclerc, B., Tchoreloff, P., 2010. Evaluation of a rotary tablet press simulator as a tool for the characterization of compaction properties of pharmaceutical products. J. Pharm. Sci. 99, 2874-2885. https://doi.org/10.1002/jps.22032

575 Paul, S., Sun, C.C., 2018. Systematic evaluation of common lubricants for optimal use in tablet formulation. Eur. J. Pharm. Sci. 117, 118-127. https://doi.org/10.1016/j.ejps.2018.02.013

Paul, S., Sun, C.C., 2017. Lubrication with magnesium stearate increases tablet brittleness. Powder Technol. 309, 126-132. https://doi.org/10.1016/j.powtec.2016.12.012

Peeters, E., Vanhoorne, V., Vervaet, C., Remon, J.P., 2016. Lubricant sensitivity in function of paddle movement in the forced feeder of a high-speed tablet press. Drug Dev. Ind. Pharm. 42, 2078-2085. https://doi.org/10.1080/03639045.2016.1200067

Pontier, C., Champion, E., Viana, M., Chulia, D., Bernache-Assollant, D., 2002. Use of cycles of compression to characterize the behaviour of apatitic phosphate powders. J. Eur. Ceram. Soc. 22, 1205-1216. https://doi.org/10.1016/S0955-2219(01)00453-8

Schulze, D., Schwedes, J., Carson, J.W., 2008. Powders and bulk solids: Behavior, characterization, storage and flow, Powders and Bulk Solids: Behavior, Characterization, Storage and Flow. https://doi.org/10.1007/978-3-540-73768-1

Sun, C.C., 2015. Dependence of ejection force on tableting speed-A compaction simulation study. Powder Technol. 279, 123-126. https://doi.org/10.1016/j.powtec.2015.04.004

590 Uzondu, B., Leung, L.Y., Mao, C., Yang, C.Y., 2018. A mechanistic study on tablet ejection force and its sensitivity to lubrication for pharmaceutical powders. Int. J. Pharm. 543, 234-244. https://doi.org/10.1016/j.ijpharm.2018.03.064

Vachon, M.G., Chulia, D., 1999. The use of energy indices in estimating powder compaction functionality of mixtures in pharmaceutical tableting. Int. J. Pharm. 177, 183-200. https://doi.org/10.1016/S03785173(98)00347-0

Van Rossum, G., Drake Jr, F.L., 1995. Python tutorial. Centrum voor Wiskunde en Informatica Amsterdam, The Netherlands.

Van Snick, B., Dhondt, J., Pandelaere, K., Bertels, J., Mertens, R., Klingeleers, D., Di Pretoro, G., Remon, 
J.P., Vervaet, C., De Beer, T., Vanhoorne, V., 2018a. A multivariate raw material property database to facilitate drug product development and enable in-silico design of pharmaceutical dry powder processes. Int. J. Pharm. 549, 415-435. https://doi.org/10.1016/j.ijpharm.2018.08.014

Van Snick, B., Grymonpré, W., Dhondt, J., Pandelaere, K., Di Pretoro, G., Remon, J.P., De Beer, T., Vervaet, C., Vanhoorne, V., 2018b. Impact of blend properties on die filling during tableting. Int. J. Pharm. 549, 476-488. https://doi.org/10.1016/j.ijpharm.2018.08.015

605 Vromans, H., Lerk, C.F., 1988. Densification properties and compactibility of mixtures of pharmaceutical excipients with and without magnesium stearate. Int. J. Pharm. 46, 183-192. https://doi.org/10.1016/0378-5173(88)90076-2

Wang, J., Wen, H., Desai, D., 2010. Lubrication in tablet formulations. Eur. J. Pharm. Biopharm. 75, 1-15. https://doi.org/10.1016/j.ejpb.2010.01.007

610 Yamamura, T., Ohta, T., Taira, T., Ogawa, Y., Sakai, Y., Moribe, K., Yamamoto, K., 2009. Effects of automated external lubrication on tablet properties and the stability of eprazinone hydrochloride. Int. J. Pharm. https://doi.org/10.1016/j.ijpharm.2008.11.007

Zuurman, K., Van Der Voort Maarschalk, K., Bolhuis, G.K., 1999. Effect of magnesium stearate on bonding and porosity expansion of tablets produced from materials with different consolidation properties. Int. J. Pharm. 179, 107-115. https://doi.org/10.1016/S0378-5173(98)00389-5 


\section{Figures}

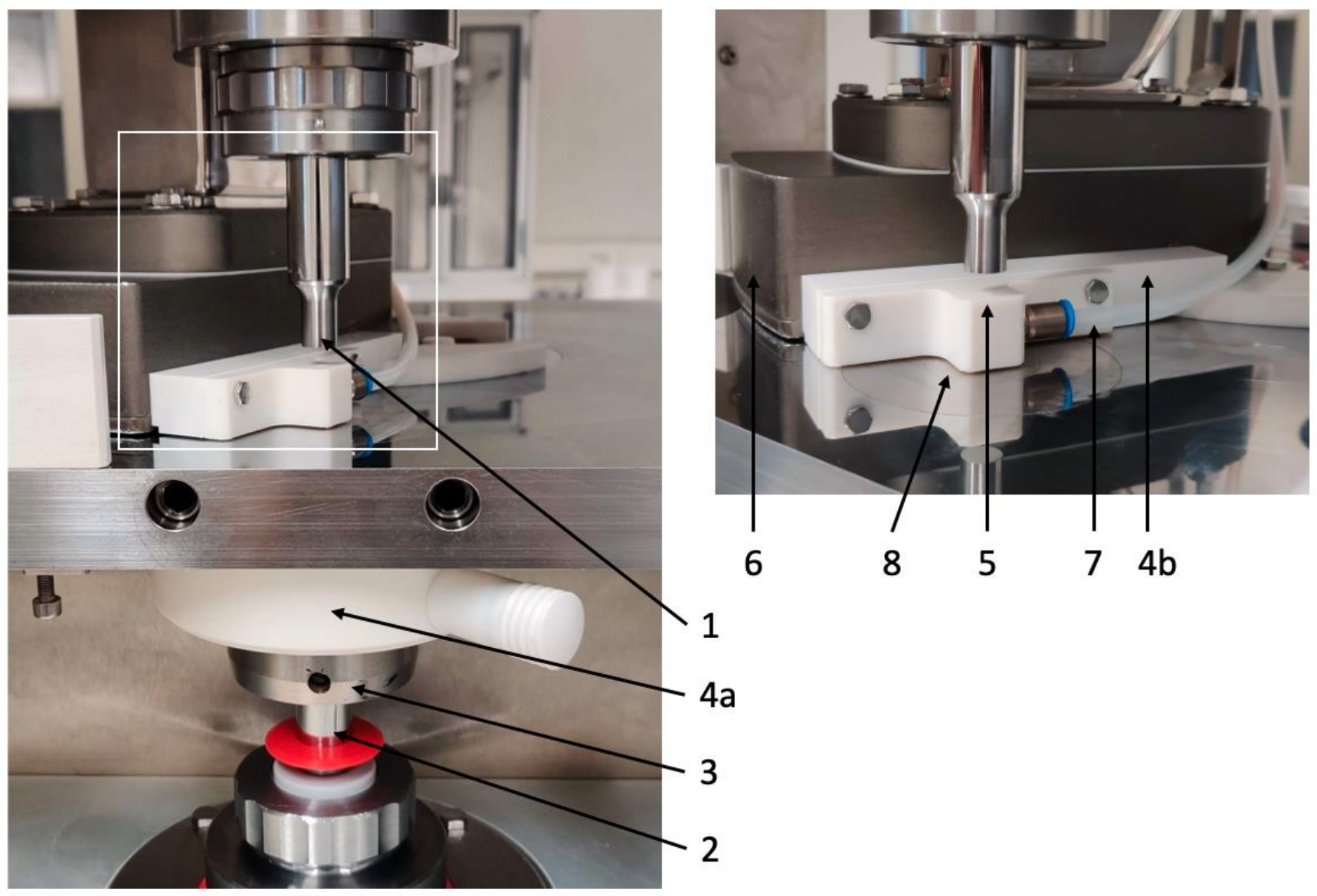

Figure 1: Illustration of the external lubrication system implemented in the compaction simulator on the lubrication position. Left: an overview of the tableting table showing the upper punch (1), lower punch (2), die holder (3) and dust extraction system $(4 a+b)^{*}$. Right: a close up of the external lubrication nozzle (5) connected to the feed shoe (6). The lubricant is dispersed from the micro-dosing unit through tubings (7) towards the spraying nozzle (5) with a double output; lubricating the upper punch (1) and lower punch (2) + die wall (8).

*The dust extraction system is not fully connected to improve visibility of the lubrication system and machine parts. 


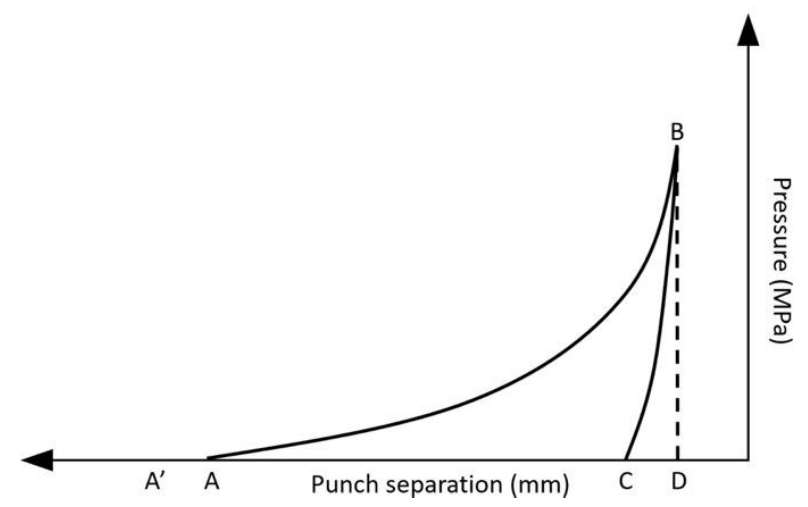

Figure 2: Force-displacement curve illustrating the different phases during compression.

630 


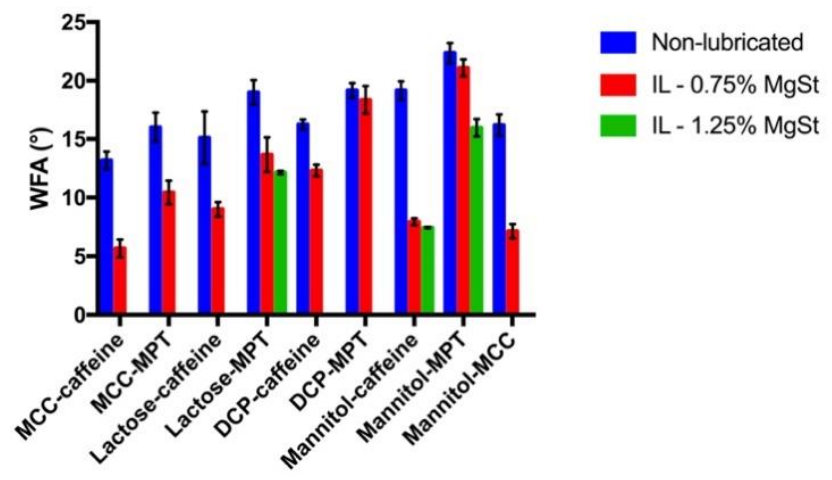

Figure 3: WFA values of the non-lubricated and internally lubricated (IL) blends. 


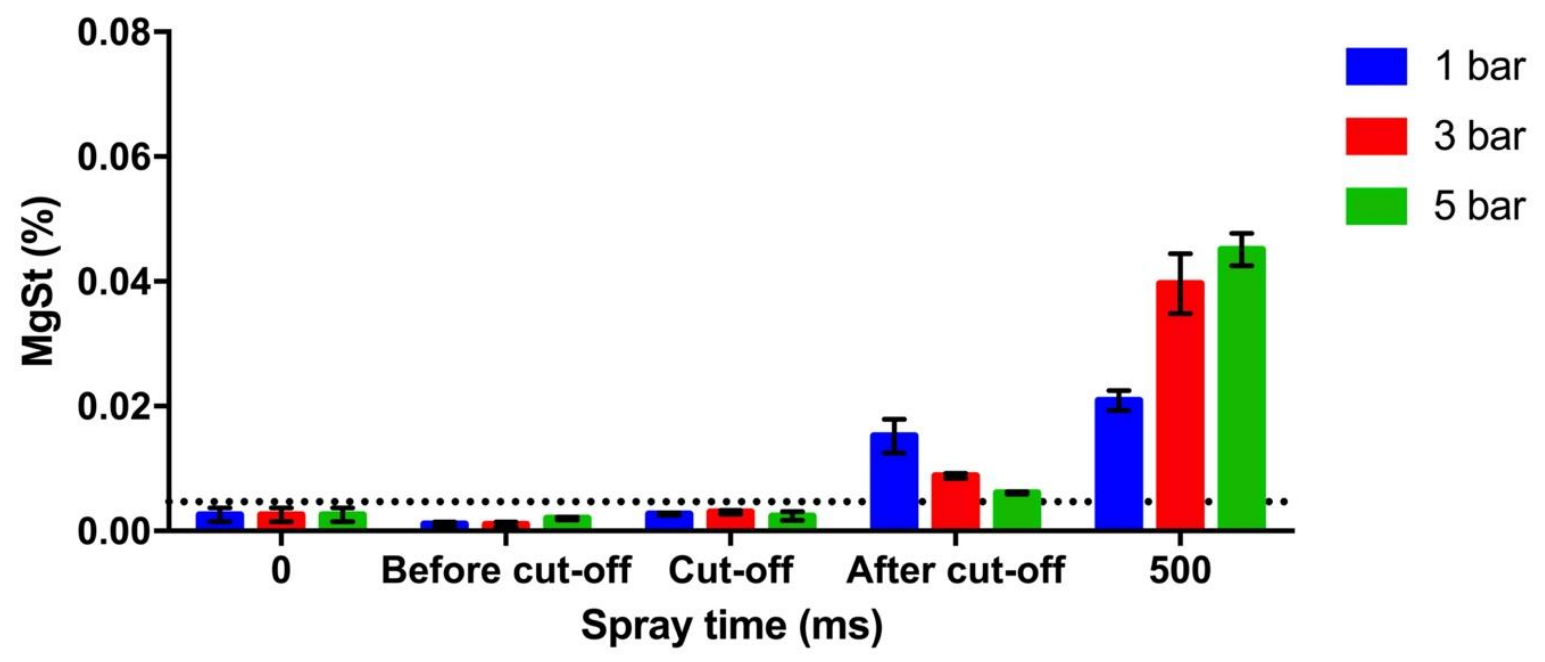

635 Figure 4: The concentration of MgSt for mannitol-MCC (MCP $65 \mathrm{MPa}$ ). Test points were taken at $0 \mathrm{ms,}$ the cut-off spraying time (Section 3.3), $10 \mathrm{~ms}$ before and $20 \mathrm{~ms}$ after this point and at $500 \mathrm{~ms}$. The dotted line represents the limit of quantification of the ICP-OES method. 


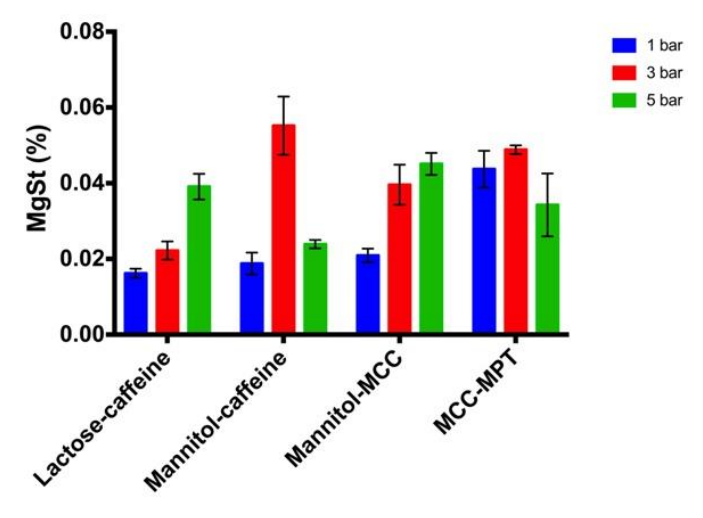

640 Figure 5: The concentration of MgSt in externally lubricated tablets in function of atomizing pressure for different formulations with a spraying time of $500 \mathrm{~ms}$. 


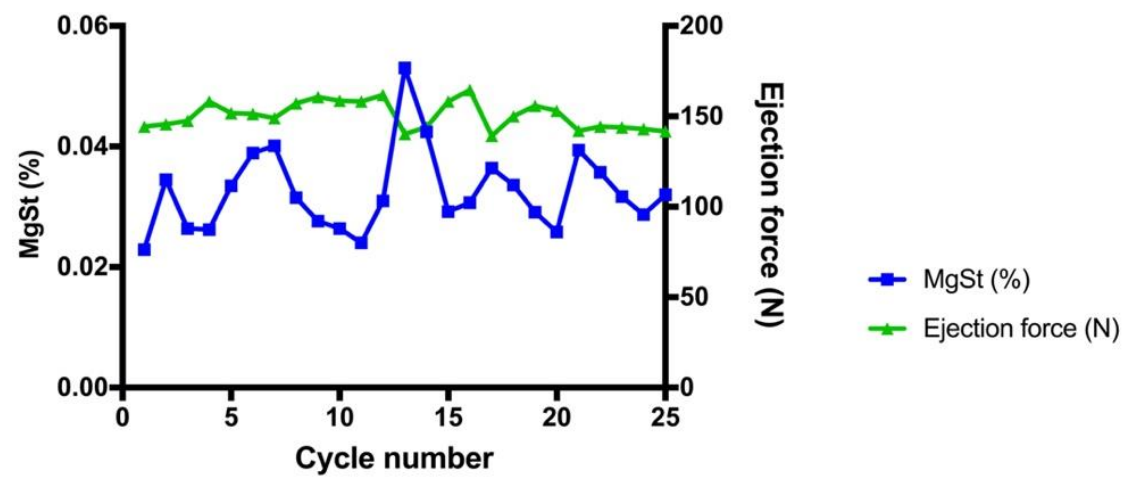

Figure 6: The concentration of MgSt (left y-axis) on externally lubricated tablets (atomizing pressure: 5 bar, spraying time: $500 \mathrm{~ms}$ ) measured in a consecutive run of 25 tablets plotted with the ejection forces (right y-axis) of lactose-caffeine (MCP $65 \mathrm{MPa})$. 

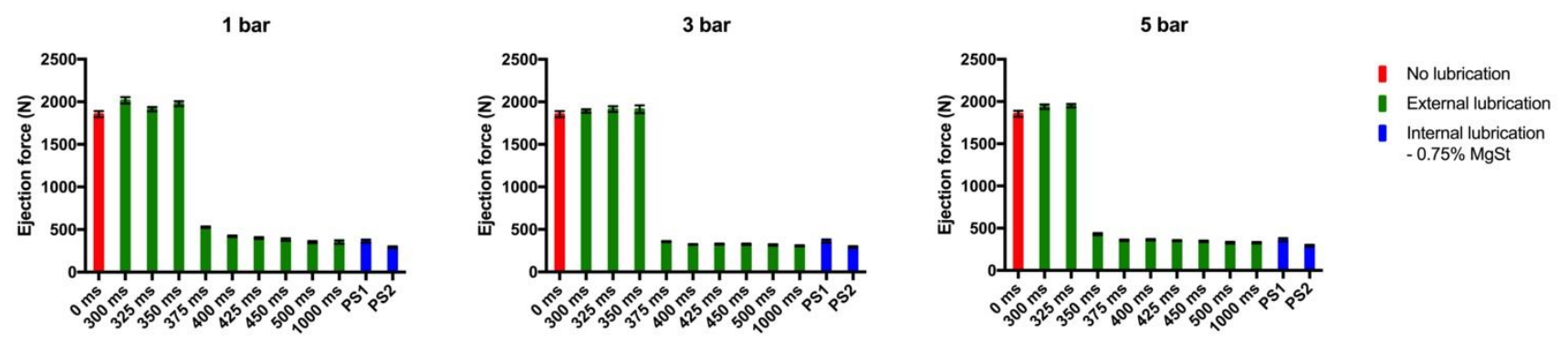

Figure 7: Ejection forces of externally lubricated tablets in function of spray time and atomizing pressure (green bars), compared to non-lubricated (red bars) and internally lubricated tablets $(0.75 \% \mathrm{MgSt}$, blue bars) for lactose-caffeine (MCP $255 \mathrm{MPa}$ ). 
DCP-caffeine (255 MPa)
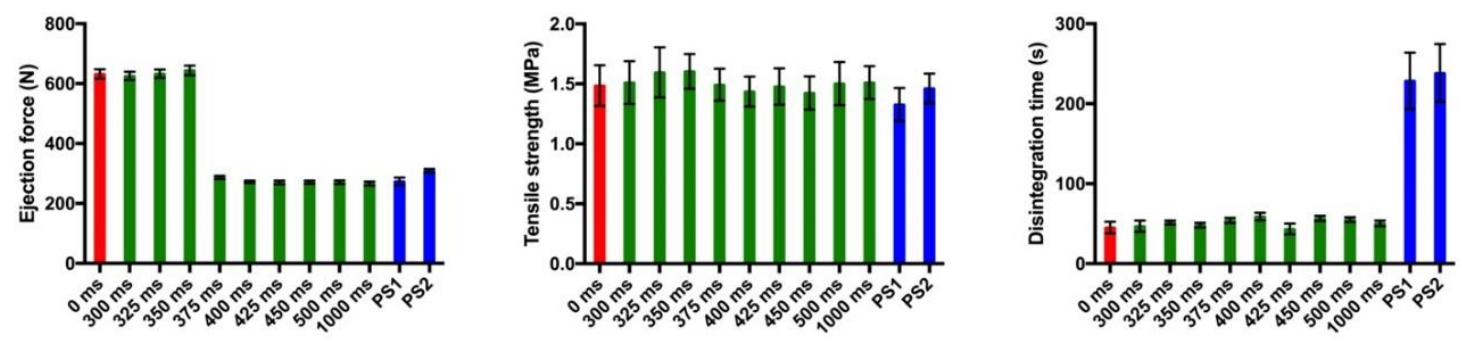

Lactose-caffeine (255 MPa)
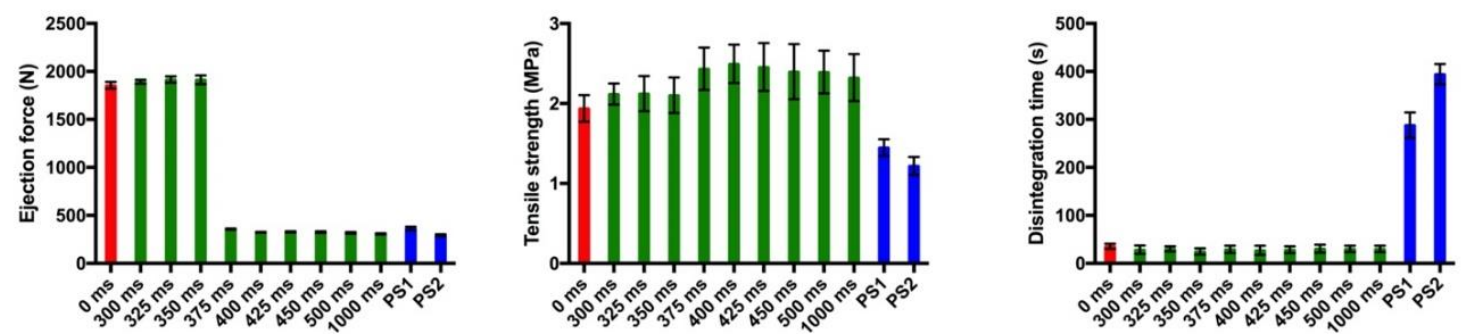

MCC-MPT (65 MPa)
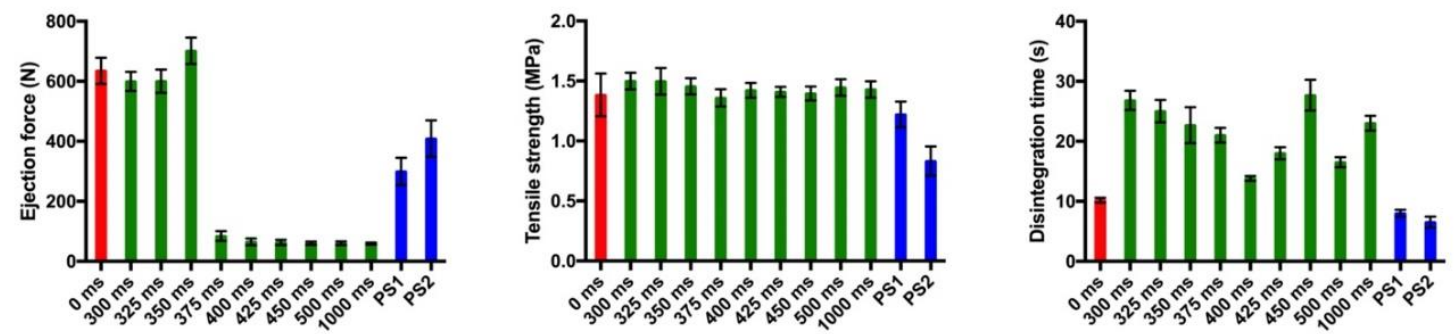

Mannitol-MPT (65 MPa)
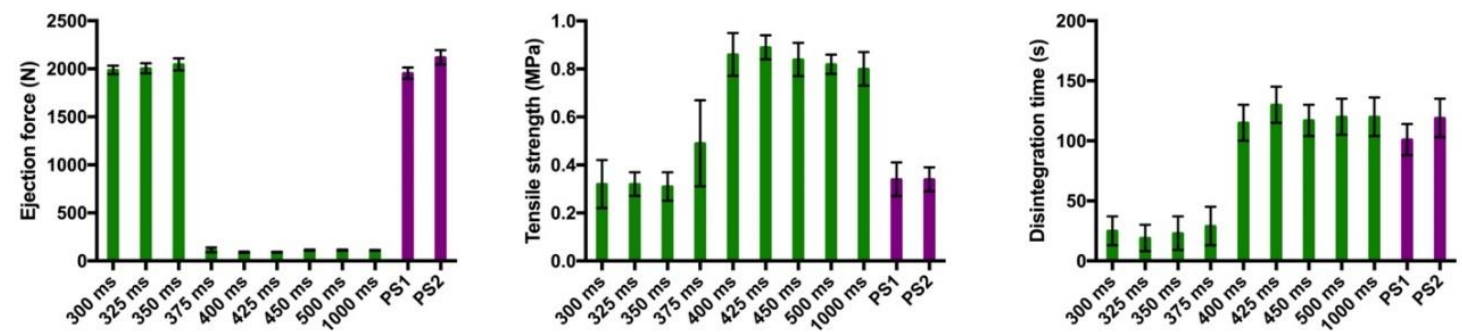

No lubrication

External lubrication

I Internal lubrication - $0.75 \% \mathrm{MgSt}$

Internal lubrication - $1.25 \% \mathrm{MgSt}$

Figure

8: Ejection forces (left), tensile strength (middle) and disintegration time (right) of externally lubricated tablets, atomizing pressure of 3 bar, compared to internally lubricated tablets ( $0.75 \%$ or $1.25 \% \mathrm{MgSt}$ ) for DCP-caffeine (255 MPa), lactose-caffeine (255 MPa), MCC-MPT (65 MPa) and mannitol-MPT (MCP 65 $\mathrm{MPa})$. 


\section{Tables}

Table 1: Overview of the included formulations.

\begin{tabular}{|c|c|c|}
\hline Formulation & Ratio (\% w/w) & Lubricant (\% MgSt) \\
\hline \multirow{2}{*}{ MCC-caffeine } & \multirow{2}{*}{$90 / 10$} & 0 \\
\hline & & 0.75 \\
\hline \multirow{2}{*}{ MCC-MPT } & \multirow{2}{*}{$90 / 10$} & 0 \\
\hline & & 0.75 \\
\hline \multirow{2}{*}{ Lactose-caffeine } & \multirow{2}{*}{$90 / 10$} & 0 \\
\hline & & 0.75 \\
\hline \multirow{3}{*}{ Lactose-MPT } & \multirow{3}{*}{$90 / 10$} & 0 \\
\hline & & 0.75 \\
\hline & & 1.25 \\
\hline \multirow{2}{*}{ DCP-caffeine } & \multirow{2}{*}{$90 / 10$} & 0 \\
\hline & & 0.75 \\
\hline \multirow{2}{*}{ DCP-MPT } & \multirow{2}{*}{$90 / 10$} & 0 \\
\hline & & 0.75 \\
\hline \multirow{3}{*}{ Mannitol-caffeine } & \multirow{3}{*}{$90 / 10$} & 0 \\
\hline & & 0.75 \\
\hline & & 1.25 \\
\hline \multirow{3}{*}{ Mannitol-MPT } & \multirow{3}{*}{$90 / 10$} & 0 \\
\hline & & 0.75 \\
\hline & & 1.25 \\
\hline \multirow{2}{*}{ Mannitol-MCC } & \multirow{2}{*}{$80 / 20$} & 0 \\
\hline & & 0.75 \\
\hline
\end{tabular}

660 
Table 2: Overview of the raw material characteristics (values are expresses as mean \pm standard deviation). (-): not possible to determine tensile strength and TBI due to insufficient tablet quality.

\begin{tabular}{llllll}
\hline Material & WFA $\left(^{\circ}\right)$ & $\begin{array}{l}\text { Specific work } \\
\text { of } \\
\text { compaction } \\
\text { (J/g) }\end{array}$ & Elasticity (\%) & $\begin{array}{l}\text { Cohesion } \\
\text { index (MPa/J) }\end{array}$ & TBI \\
\hline MCC & $9.9 \pm 1.4$ & $33.9 \pm 0.6$ & $3.2 \pm 0.0$ & $0.67 \pm 0.02$ & $24.9 \pm 0.6$ \\
\hline Lactose & $16.1 \pm 1.3$ & $17.7 \pm 0.1$ & $4.1 \pm 0.1$ & $0.21 \pm 0.02$ & $136.1 \pm 4.2$ \\
\hline DCP & $13.1 \pm 1.5$ & $17.2 \pm 0.1$ & $3.2 \pm 0.1$ & $0.20 \pm 0.01$ & $135.6 \pm 2.5$ \\
\hline Mannitol & $19.6 \pm 0.6$ & $24.9 \pm 0.1$ & $3.1 \pm 0.0$ & $0.32 \pm 0.02$ & $62.3 \pm 4.1$ \\
\hline Caffeine & $17.4 \pm 1.6$ & $20.4 \pm 1.0$ & $4.7 \pm 0.2$ & $0.32 \pm 0.05$ & $99.1 \pm 4.1$ \\
\hline MPT & $34.6 \pm 2.1$ & $19.2 \pm 0.1$ & $7.3 \pm 0.1$ & - & - \\
\hline MgSt & $8.7 \pm 0.8$ & $7.5 \pm 0.4$ & $28.4 \pm 2.0$ & - & - \\
\hline
\end{tabular}




\section{Supplementary data}

Table S1: Overview of the blend characteristics (values are expresses as mean \pm standard deviation).

\begin{tabular}{|c|c|c|c|c|c|c|c|}
\hline Formulation & $\begin{array}{l}\text { Lubricant } \\
\text { MgSt) }\end{array}$ & $(\%$ & WFA $\left(^{\circ}\right)$ & $\begin{array}{l}\text { Specific work of } \\
\text { compaction }(\mathrm{J} / \mathrm{g})\end{array}$ & Elasticity (\%) & $\begin{array}{l}\text { Cohesion index } \\
(\mathrm{MPa} / \mathrm{J})\end{array}$ & TBI \\
\hline \multirow{2}{*}{ MCC-caffeine } & 0 & & $13.2 \pm 0.8$ & $32.0 \pm 0.5$ & $3.23 \pm 0.1$ & $0.57 \pm 0.02$ & $31.2 \pm 1.4$ \\
\hline & 0.75 & & $5.7 \pm 0.8$ & $31.9 \pm 0.8$ & $3.33 \pm 0.0$ & $0.53 \pm 0.00$ & $33.4 \pm 1.6$ \\
\hline \multirow{2}{*}{ MCC-MPT } & 0 & & $16.0 \pm 1.3$ & $32.4 \pm 0.7$ & $3.32 \pm 0.1$ & $0.47 \pm 0.02$ & $36.1 \pm 2.0$ \\
\hline & 0.75 & & $10.4 \pm 1.0$ & $31.3 \pm 0.9$ & $3.48 \pm 0.1$ & $0.37 \pm 0.00$ & $44.2 \pm 0.5$ \\
\hline \multirow{2}{*}{ Lactose-caffeine } & 0 & & $15.1 \pm 2.3$ & $16.7 \pm 0.1$ & $4.33 \pm 0.0$ & $0.21 \pm 0.02$ & $156.1 \pm 10.4$ \\
\hline & 0.75 & & $9.0 \pm 0.6$ & $15.3 \pm 0.0$ & $4.70 \pm 0.0$ & $0.14 \pm 0.01$ & $184.2 \pm 5.1$ \\
\hline \multirow{3}{*}{ Lactose-MPT } & 0 & & $19.0 \pm 1.1$ & $16.2 \pm 0.0$ & $4.19 \pm 0.0$ & $0.21 \pm 0.02$ & $218.2 \pm 21.4$ \\
\hline & 0.75 & & $13.7 \pm 1.5$ & $15.6 \pm 0.1$ & $4.28 \pm 0.0$ & $0.18 \pm 0.01$ & $305.9 \pm 24.9$ \\
\hline & 1.25 & & $12.1 \pm 0.2$ & $15.2 \pm 0.1$ & $4.42 \pm 0.1$ & $0.15 \pm 0.00$ & $345.6 \pm 14.7$ \\
\hline \multirow{2}{*}{ DCP-caffeine } & 0 & & $16.3 \pm 0.4$ & $15.6 \pm 0.1$ & $3.26 \pm 0.1$ & $0.22 \pm 0.01$ & $119.5 \pm 5.3$ \\
\hline & 0.75 & & $12.3 \pm 0.5$ & $15.3 \pm 0.1$ & $3.36 \pm 0.1$ & $0.21 \pm 0.01$ & $130.8 \pm 3.3$ \\
\hline \multirow{2}{*}{ DCP-MPT } & 0 & & $19.2 \pm 0.6$ & $15.1 \pm 0.2$ & $3.33 \pm 0.1$ & $0.21 \pm 0.01$ & $148.3 \pm 2.1$ \\
\hline & 0.75 & & $18.4 \pm 1.2$ & $14.8 \pm 0.1$ & $3.63 \pm 0.1$ & $0.20 \pm 0.01$ & $159.1 \pm 2.7$ \\
\hline \multirow{3}{*}{ Mannitol-caffeine } & 0 & & $19.2 \pm 0.8$ & $24.8 \pm 0.1$ & $2.72 \pm 0.0$ & $0.32 \pm 0.01$ & $57.0 \pm 1.8$ \\
\hline & 0.75 & & $7.9 \pm 0.3$ & $24.2 \pm 0.1$ & $2.90 \pm 0.0$ & $0.32 \pm 0.01$ & $57.9 \pm 2.2$ \\
\hline & 1.25 & & $7.4 \pm 0.1$ & $23.7 \pm 0.1$ & $2.97 \pm 0.1$ & $0.29 \pm 0.01$ & $69.5 \pm 1.9$ \\
\hline \multirow{2}{*}{ Mannitol-MPT } & 0 & & $22.4 \pm 0.9$ & $26.5 \pm 0.4$ & $2.34 \pm 0.1$ & $0.34 \pm 0.01$ & $56.5 \pm 1.8$ \\
\hline & 0.75 & & $21.1 \pm 0.7$ & $24.9 \pm 0.6$ & $2.75 \pm 0.1$ & $0.31 \pm 0.02$ & $64.1 \pm 1.6$ \\
\hline
\end{tabular}




\begin{tabular}{llllllll}
\hline & 1.25 & $16.0 \pm 0.8$ & $24.9 \pm 0.4$ & $2.84 \pm 0.1$ & $0.29 \pm 0.00$ & $69.6 \pm 3.8$ \\
\hline \multirow{2}{*}{ Mannitol-MCC } & 0 & $16.2 \pm 0.9$ & $26.6 \pm 0.1$ & $3.01 \pm 0.0$ & $0.34 \pm 0.01$ & $56.8 \pm 2.4$ \\
\cline { 2 - 7 } & 0.75 & $7.1 \pm 0.6$ & $25.9 \pm 0.1$ & $3.16 \pm 0.0$ & $0.30 \pm 0.01$ & $66.0 \pm 3.5$ \\
\hline
\end{tabular}


Table S2: Overview of the ejection forces of the different formulations using no lubrication, external and internal lubrication (values are expresses as mean \pm standard deviation). (EF overload): no data due to excessively high ejection forces. (-): experiments were not conducted.

\begin{tabular}{|c|c|c|c|c|c|c|c|c|c|}
\hline \multicolumn{2}{|c|}{ Formulation } & \multicolumn{8}{|c|}{ Ejection force (N) } \\
\hline & & \multirow{3}{*}{$\begin{array}{l}\text { Non- } \\
\text { lubricated }\end{array}$} & \multirow{2}{*}{\multicolumn{3}{|c|}{$\begin{array}{l}\text { External lubrication } \\
\mathbf{5 0 0 ~ m s}\end{array}$}} & \multicolumn{4}{|c|}{ Internal lubrication } \\
\hline & & & & & & \multicolumn{2}{|l|}{ 0.75\% MgSt } & \multicolumn{2}{|l|}{$1.25 \% \mathrm{MgSt}$} \\
\hline & & & 1 bar & 3 bar & 5 bar & PS1 & PS2 & PS1 & PS2 \\
\hline MCC- & $65 \mathrm{MPa}$ & $231 \pm 24$ & $96 \pm 7$ & $97 \pm 10$ & $86 \pm 4$ & $105 \pm 8$ & $98 \pm 5$ & - & - \\
\hline caffeine & $255 \mathrm{MPa}$ & $116 \pm 9$ & $55 \pm 4$ & $61 \pm 3$ & $59 \pm 3$ & $39 \pm 8$ & $54 \pm 18$ & - & - \\
\hline \multirow[t]{2}{*}{ MCC-MPT } & $65 \mathrm{MPa}$ & $635 \pm 43$ & $101 \pm 17$ & $60 \pm 7$ & $72 \pm 9$ & $299 \pm 46$ & $409 \pm 61$ & - & - \\
\hline & $255 \mathrm{MPa}$ & $497 \pm 42$ & $70 \pm 10$ & $45 \pm 4$ & $49 \pm 6$ & $219 \pm 18$ & $251 \pm 14$ & - & - \\
\hline \multirow{2}{*}{$\begin{array}{l}\text { Lactose- } \\
\text { caffeine }\end{array}$} & $65 \mathrm{MPa}$ & $508 \pm 11$ & $147 \pm 14$ & $122 \pm 11$ & $151 \pm 7$ & $148 \pm 20$ & $94 \pm 6$ & - & - \\
\hline & $255 \mathrm{MPa}$ & $1856 \pm 36$ & $352 \pm 14$ & $317 \pm 10$ & $328 \pm 11$ & $364 \pm 20$ & $293 \pm 9$ & - & - \\
\hline Lactose- & $65 \mathrm{MPa}$ & EF overload & $73 \pm 17$ & $73 \pm 8$ & $73 \pm 8$ & EF overload & EF overload & $629 \pm 60$ & $1002 \pm 41$ \\
\hline MPT & $255 \mathrm{MPa}$ & EF overload & $581 \pm 26$ & $210 \pm 7$ & $206 \pm 12$ & EF overload & EF overload & EF overload & EF overload \\
\hline \multirow{2}{*}{$\begin{array}{l}\text { DCP- } \\
\text { caffeine }\end{array}$} & $65 \mathrm{MPa}$ & $189 \pm 14$ & $73 \pm 4$ & $70 \pm 3$ & $89 \pm 10$ & $75 \pm 6$ & $74 \pm 5$ & - & - \\
\hline & $255 \mathrm{MPa}$ & $632 \pm 15$ & $298 \pm 6$ & $271 \pm 6$ & $298 \pm 6$ & $274 \pm 13$ & $309 \pm 6$ & - & - \\
\hline \multirow{2}{*}{$\begin{array}{l}\text { Mannitol- } \\
\text { caffeine }\end{array}$} & $65 \mathrm{MPa}$ & $1591 \pm 51$ & $189 \pm 25$ & $132 \pm 14$ & $128 \pm 11$ & $116 \pm 8$ & $121 \pm 7$ & $103 \pm 11$ & $97 \pm 8$ \\
\hline & $255 \mathrm{MPa}$ & EF overload & $1634 \pm 52$ & $594 \pm 24$ & $598 \pm 31$ & $1032 \pm 46$ & $1270 \pm 45$ & $364 \pm 7$ & $410 \pm 19$ \\
\hline \multirow{2}{*}{$\begin{array}{l}\text { Mannitol- } \\
\text { MPT }\end{array}$} & $65 \mathrm{MPa}$ & EF overload & $146 \pm 6$ & $111 \pm 6$ & $127 \pm 6$ & EF overload & EF overload & $1956 \pm 59$ & $2120 \pm 76$ \\
\hline & $255 \mathrm{MPa}$ & EF overload & $1780 \pm 24$ & $905 \pm 40$ & $1367 \pm 35$ & EF overload & EF overload & EF overload & EF overload \\
\hline Mannitol- & $65 \mathrm{MPa}$ & $1785 \pm 32$ & $261 \pm 37$ & $81 \pm 5$ & $82 \pm 3$ & $102 \pm 12$ & $76 \pm 5$ & - & - \\
\hline $\mathrm{MCC}$ & $255 \mathrm{MPa}$ & EF overload & $532 \pm 60$ & $249 \pm 12$ & $254 \pm 12$ & $231 \pm 3$ & $224 \pm 4$ & - & - \\
\hline
\end{tabular}


Table S3: Overview of the tensile strength of the different formulations using no lubrication, external and internal lubrication (values are expresses as mean \pm standard deviation). (EF overload): no data due to excessively high ejection forces. (-): experiments were not conducted.

\begin{tabular}{|c|c|c|c|c|c|c|c|c|c|}
\hline \multicolumn{2}{|c|}{ Formulation } & \multicolumn{8}{|c|}{ Tensile strength (MPa) } \\
\hline & & \multirow{3}{*}{$\begin{array}{l}\text { Non- } \\
\text { lubricated }\end{array}$} & \multirow{2}{*}{\multicolumn{3}{|c|}{$\begin{array}{l}\text { External lubrication } \\
500 \mathrm{~ms}\end{array}$}} & \multicolumn{4}{|c|}{ Internal lubrication } \\
\hline & & & & & & \multicolumn{2}{|l|}{$0.75 \% \mathrm{MgSt}$} & \multicolumn{2}{|l|}{$1.25 \% \mathrm{MgSt}$} \\
\hline & & & 1 bar & 3 bar & 5 bar & PS1 & PS2 & PS1 & PS2 \\
\hline MCC- & $65 \mathrm{MPa}$ & $2.5 \pm 0.2$ & $2.6 \pm 0.1$ & $2.5 \pm 0.1$ & $2.8 \pm 0.1$ & $2.2 \pm 0.1$ & $1.8 \pm 0.0$ & - & - \\
\hline caffeine & $255 \mathrm{MPa}$ & $7.9 \pm 0.3$ & $8.0 \pm 0.3$ & $7.3 \pm 0.7$ & $7.6 \pm 0.3$ & $6.6 \pm 0.3$ & $4.6 \pm 0.2$ & - & - \\
\hline \multirow[t]{2}{*}{ MCC-MPT } & $65 \mathrm{MPa}$ & $1.4 \pm 0.2$ & $1.5 \pm 0.1$ & $1.5 \pm 0.1$ & $1.3 \pm 0.1$ & $1.2 \pm 0.2$ & $0.8 \pm 0.1$ & - & - \\
\hline & $255 \mathrm{MPa}$ & $4.0 \pm 0.5$ & $3.8 \pm 0.3$ & $4.0 \pm 0.3$ & $4.0 \pm 0.2$ & $2.6 \pm 0.2$ & $2.1 \pm 0.1$ & - & - \\
\hline \multirow{2}{*}{$\begin{array}{l}\text { Lactose- } \\
\text { caffeine }\end{array}$} & $65 \mathrm{MPa}$ & $0.5 \pm 0.1$ & $0.6 \pm 0.1$ & $0.5 \pm 0.1$ & $0.6 \pm 0.0$ & $0.2 \pm 0.0$ & $0.2 \pm 0.0$ & - & - \\
\hline & $255 \mathrm{MPa}$ & $1.9 \pm 0.2$ & $2.3 \pm 0.3$ & $2.4 \pm 0.3$ & $2.5 \pm 0.2$ & $1.5 \pm 0.1$ & $1.2 \pm 0.1$ & - & - \\
\hline Lactose- & $65 \mathrm{MPa}$ & EF overload & $0.3 \pm 0.1$ & $0.3 \pm 0.0$ & $0.38 \pm 0.0$ & EF overload & EF overload & $0.2 \pm 0.0$ & $0.2 \pm 0.1$ \\
\hline MPT & $255 \mathrm{MPa}$ & EF overload & $1.7 \pm 0.2$ & $1.6 \pm 0.2$ & $1.61 \pm 0.1$ & EF overload & EF overload & EF overload & EF overload \\
\hline \multirow{2}{*}{$\begin{array}{l}\text { DCP- } \\
\text { caffeine }\end{array}$} & $65 \mathrm{MPa}$ & $0.2 \pm 0.0$ & $0.2 \pm 0.0$ & $0.2 \pm 0.0$ & $0.2 \pm 0.0$ & $0.2 \pm 0.0$ & $0.2 \pm 0.0$ & - & - \\
\hline & $255 \mathrm{MPa}$ & $1.5 \pm 0.2$ & $1.4 \pm 0.1$ & $1.5 \pm 0.2$ & $1.5 \pm 0.1$ & $1.2 \pm 0.1$ & $1.5 \pm 0.1$ & - & - \\
\hline \multirow{2}{*}{$\begin{array}{l}\text { Mannitol- } \\
\text { caffeine }\end{array}$} & $65 \mathrm{MPa}$ & $0.8 \pm 0.1$ & $1.2 \pm 0.1$ & $1.4 \pm 0.1$ & $1.4 \pm 0.0$ & $0.8 \pm 0.0$ & $0.7 \pm 0.0$ & $0.9 \pm 0.0$ & $0.82 \pm 0.1$ \\
\hline & $255 \mathrm{MPa}$ & EF overload & $3.7 \pm 0.4$ & $3.3 \pm 0.3$ & $3.3 \pm 0.2$ & $3.1 \pm 0.3$ & $3.0 \pm 0.3$ & $3.0 \pm 0.2$ & $2.7 \pm 0.2$ \\
\hline Mannitol- & $65 \mathrm{MPa}$ & EF overload & $0.8 \pm 0.0$ & $0.8 \pm 0.0$ & $0.7 \pm 0.1$ & EF overload & EF overload & $0.3 \pm 0.1$ & $0.3 \pm 0.1$ \\
\hline MPT & $255 \mathrm{MPa}$ & EF overload & $3.2 \pm 0.4$ & $2.5 \pm 0.4$ & $3.1 \pm 0.4$ & EF overload & EF overload & EF overload & EF overload \\
\hline Mannitol- & $65 \mathrm{MPa}$ & $0.5 \pm 0.0$ & $0.9 \pm 0.1$ & $1.0 \pm 0.0$ & $0.9 \pm 0.0$ & $0.6 \pm 0.0$ & $0.5 \pm 0.0$ & - & - \\
\hline MCC & $255 \mathrm{MPa}$ & EF overload & $4.2 \pm 0.4$ & $4.5 \pm 0.3$ & $4.2 \pm 0.4$ & $3.2 \pm 0.2$ & $3.0 \pm 0.2$ & - & - \\
\hline
\end{tabular}


Table S4: Overview of the disintegration time of the different formulations using no lubrication, external and internal lubrication (values are expresses as mean \pm standard deviation). (EF overload): no data due to excessively high ejection forces. (-): experiments were not conducted.

\begin{tabular}{|c|c|c|c|c|c|c|c|c|c|}
\hline \multicolumn{2}{|c|}{ Formulation } & \multicolumn{8}{|c|}{ Disintegration time (s) } \\
\hline & & \multirow{3}{*}{$\begin{array}{l}\text { Non- } \\
\text { lubricated }\end{array}$} & \multirow{2}{*}{\multicolumn{3}{|c|}{$\begin{array}{l}\text { External lubrication } \\
500 \mathrm{~ms}\end{array}$}} & \multicolumn{4}{|c|}{ Internal lubrication } \\
\hline & & & & & & \multicolumn{2}{|l|}{$0.75 \% \mathrm{MgSt}$} & \multicolumn{2}{|l|}{$1.25 \% \mathrm{MgSt}$} \\
\hline & & & 1 bar & 3 bar & 5 bar & PS1 & PS2 & PS1 & PS2 \\
\hline MCC- & $65 \mathrm{MPa}$ & $7 \pm 1$ & $7 \pm 1$ & $8 \pm 1$ & $8 \pm 1$ & $17 \pm 1$ & $18 \pm 1$ & - & - \\
\hline caffeine & $255 \mathrm{MPa}$ & $130 \pm 12$ & $97 \pm 9$ & $119 \pm 11$ & $111 \pm 13$ & $123 \pm 20$ & $79 \pm 18$ & - & - \\
\hline \multirow[t]{2}{*}{ MCC-MPT } & $65 \mathrm{MPa}$ & $10 \pm 0$ & $21 \pm 1$ & $17 \pm 1$ & $19 \pm 2$ & $8 \pm 1$ & $7 \pm 1$ & - & - \\
\hline & $255 \mathrm{MPa}$ & $1365 \pm 63$ & $1329 \pm 64$ & $1490 \pm 59$ & $1409 \pm 28$ & $1030 \pm 52$ & $820 \pm 90$ & - & - \\
\hline \multirow{2}{*}{$\begin{array}{l}\text { Lactose- } \\
\text { caffeine }\end{array}$} & $65 \mathrm{MPa}$ & $24 \pm 4$ & $31 \pm 6$ & $28 \pm 4$ & $28 \pm 3$ & $105 \pm 13$ & $171 \pm 15$ & - & - \\
\hline & $255 \mathrm{MPa}$ & $36 \pm 5$ & $31 \pm 6$ & $30 \pm 7$ & $28 \pm 3$ & $288 \pm 26$ & $394 \pm 21$ & - & - \\
\hline \multirow{2}{*}{$\begin{array}{l}\text { Lactose- } \\
\text { MPT }\end{array}$} & $65 \mathrm{MPa}$ & EF overload & $40 \pm 1$ & $31 \pm 2$ & $37 \pm 4$ & EF overload & EF overload & $130 \pm 25$ & $140 \pm 31$ \\
\hline & $255 \mathrm{MPa}$ & EF overload & $416 \pm 28$ & $434 \pm 14$ & $383 \pm 18$ & EF overload & EF overload & EF overload & EF overload \\
\hline \multirow{2}{*}{$\begin{array}{l}\text { DCP- } \\
\text { caffeine }\end{array}$} & $65 \mathrm{MPa}$ & $8 \pm 0$ & $12 \pm 0$ & $9 \pm 1$ & $9 \pm 1$ & $40 \pm 7$ & $90 \pm 16$ & - & - \\
\hline & $255 \mathrm{MPa}$ & $45 \pm 7$ & $60 \pm 3$ & $55 \pm 3$ & $50 \pm 4$ & $229 \pm 35$ & $238 \pm 36$ & - & - \\
\hline \multirow{2}{*}{$\begin{array}{l}\text { Mannitol- } \\
\text { caffeine }\end{array}$} & $65 \mathrm{MPa}$ & $17 \pm 2$ & $15 \pm 4$ & $16 \pm 5$ & $16 \pm 4$ & $39 \pm 18$ & $97 \pm 22$ & $93 \pm 20$ & $128 \pm 12$ \\
\hline & $255 \mathrm{MPa}$ & EF overload & $105 \pm 6$ & $127 \pm 12$ & $138 \pm 5$ & $135 \pm 3$ & $155 \pm 7$ & $148 \pm 7$ & $185 \pm 8$ \\
\hline \multirow{2}{*}{$\begin{array}{l}\text { Mannitol- } \\
\text { MPT }\end{array}$} & $65 \mathrm{MPa}$ & EF overload & $74 \pm 18$ & $120 \pm 15$ & $121 \pm 12$ & EF overload & EF overload & $101 \pm 13$ & $119 \pm 16$ \\
\hline & $255 \mathrm{MPa}$ & EF overload & $184 \pm 7$ & $195 \pm 15$ & $200 \pm 11$ & EF overload & EF overload & EF overload & EF overload \\
\hline Mannitol- & $65 \mathrm{MPa}$ & $7 \pm 1$ & $6 \pm 1$ & $6 \pm 1$ & $6 \pm 1$ & $14 \pm 3$ & $19 \pm 4$ & - & - \\
\hline MCC & $255 \mathrm{MPa}$ & EF overload & $39 \pm 3$ & $46 \pm 5$ & $42 \pm 6$ & $75 \pm 12$ & $117 \pm 6$ & - & - \\
\hline
\end{tabular}

